\title{
Stratosphere over Dumont d'Urville, Antarctica, in winter 1992
}

\author{
P. Ricaud, ${ }^{1}$ E. Monnier, ${ }^{1}$ F. Goutail, ${ }^{2}$ J.-P. Pommereau, ${ }^{2}$ C. David, ${ }^{3}$ \\ S. Godin, ${ }^{3}$ L. Froidevaux, ${ }^{4}$ J. W. Waters, ${ }^{4}$ J. Mergenthaler, ${ }^{5}$ \\ A. E. Roche ${ }^{5}$ H. Pumphrey, ${ }^{6}$ and M. P. Chipperfield ${ }^{7}$
}

\begin{abstract}
We present an analysis of the temporal evolution of stratospheric constituents above the station of Dumont d'Urville in Antarctica $\left(67^{\circ} \mathrm{S}, 140^{\circ} \mathrm{E}\right)$ from August 14 to September 20,1992. Data sets include temperature profiles and $\mathrm{H}_{2} \mathrm{O}, \mathrm{ClO}, \mathrm{O}_{3}, \mathrm{NO}_{2}, \mathrm{ClONO}_{2}, \mathrm{HNO}_{3}, \mathrm{~N}_{2} \mathrm{O}$, and $\mathrm{CH}_{4}$ mixing ratios and aerosol extinction coefficients from 46 to $1 \mathrm{hPa}$ measured by the Microwave Limb Sounder (MLS) and the Cryogenic Limb Array Etalon Spectrometer (CLAES) instruments aboard the Upper Atmosphere Research Satellite (UARS). At the station, aerosol extinction coefficients and $\mathrm{O}_{3}$ profiles are obtained by a lidar together with $\mathrm{O}_{3}$ profiles provided by sondes. Integrated $\mathrm{O}_{3}$ and $\mathrm{NO}_{2}$ column amounts are given by a Système d'Analyse par Observation Zénithale (SAOZ) spectrometer located at the station. Column $\mathrm{O}_{3}$ is also provided by the Total Ozone Mapping Spectrometer (TOMS) instrument aboard the NIMBUS 7 satellite, complemented with potential vorticity derived from the U.K. Meteorological Office assimilated data set and temperature fields provided by the European Centre for Medium-Range Weather Forecasts. Time evolution of these measurements is interpreted by comparison with results from the SLIMCAT three-dimensional chemical transport model. We show that the site is near the vortex edge on average and is alternately inside the vortex or just outside in the region referred to as the "collar" region. There are no observations of polar stratospheric clouds (PSCs) over the station above $46 \mathrm{hPa}$ $(\sim 18 \mathrm{~km})$. In fact, PSCs mainly appear over the Palmer Peninsula area at $46 \mathrm{hPa}$. The rates of change of chemical species are evaluated at $46 \mathrm{hPa}$ when the station is conservatively inside the vortex collar region. The ozone loss rate is $0.04 \mathrm{ppmv} \mathrm{d}^{-1}$ $\left(\sim 1.3 \% \mathrm{~d}^{-1}\right)$, which is consistent with other analyses of southern vortex ozone loss rates; chlorine monoxide tends to decrease by $0.03 \mathrm{ppbv} \mathrm{d}^{-1}$, while chlorine nitrate increases by $0.025 \mathrm{ppbv} \mathrm{d}^{-1}$. These negative $\mathrm{ClO}$ and positive $\mathrm{ClONO}_{2}$ trends are only observed in the collar region of the vortex where $\mathrm{O}_{3}$ amounts are far from near zero, and little denitrification is observed. Loss and production rates as measured by UARS are more pronounced than the ones deduced from the SLIMCAT model, probably because of the moderate model horizontal resolution $\left(3.75^{\circ} \times 3.75^{\circ}\right)$, which is not high enough to resolve the vortex crossings above Dumont d'Urville and which leads to a larger extent of denitrified air than indicated by the UARS data. The analysis also shows activated $\mathrm{ClO}$ inside the vortex at $46 \mathrm{hPa}$, a dehydrated vortex at $46 \mathrm{hPa}$, and rehydrated above, with no trace of denitrification in the lower stratosphere. Good agreement between coincident measurements of $\mathrm{O}_{3}$ profiles by UARS/MLS, lidar, and sondes is also observed. Finally, the agreement between UARS and SLIMCAT data sets is much better in the middle stratosphere $(4.6 \mathrm{hPa})$ than in the lower stratosphere $(46 \mathrm{hPa})$.
\end{abstract}

\section{Introduction}

Because of the particular climatic environment, connected to the presence of the vortex, chemical and physical conditions of the lower stratosphere above Antarctica create a propitious environment for what is now commonly referred to as the "ozone hole" [Solomon,

Copyright 1998 by the American Geophysical Union.

Paper number 98JD00689.

0148-0227/98/98JD-00689\$09.00

\footnotetext{
${ }^{1}$ Bordeaux Observatory, CNRS/INSU, Floirac, France. 2Service d'Aéronomie, CNRS/INSU, Verrières-Le-Buisson, France.

${ }^{3}$ Service d'Aéronomie, CNRS/INSU, Université de Jussieu, Paris, France.

4 Jet Propulsion Laboratory, Pasadena, California.

${ }^{5}$ Lockheed Martin Advanced Technology Center, Palo Alto, California.

${ }^{6}$ Department of Meteorology, University of Edimburgh, Scotland.

${ }^{7}$ Department of Chemistry, University of Cambridge, England.
} 
1990]. Ozone-depleted areas correlate well with chlorineactivated regions where the temperature is low enough to produce polar stratospheric clouds (PSCs) on which chlorine reservoirs $\left(\mathrm{HCl}\right.$ and $\left.\mathrm{ClONO}_{2}\right)$ transform into active chlorine ( $\mathrm{ClO}$ and its dimer $\mathrm{Cl}_{2} \mathrm{O}_{2}$ ) through heterogeneous reactions [see, e.g., Waters et al., 1993]. Both PSC and chlorine partitioning analyses are important issues for quantifying the extent to which $\mathrm{O}_{3}$ is depleted. Indeed, Prather and Jaffe [1990] pointed out that when the $\mathrm{O}_{3}$ concentration is very low in a denitrified atmosphere, the production of ClO slows and stabilizes [Santee et al., 1996]. However, at the vortex edge, where $\mathrm{ClONO}_{2}$ and $\mathrm{NO}_{2}$ amounts are not negligible, Douglass et al. [1995] show that $\mathrm{ClO}$ may decrease by reaction with $\mathrm{NO}_{2}$ to give $\mathrm{ClONO}_{2}$. A site at the vortex edge is well suited to observe differences in the chemistry within the vortex and in the "collar" region, as Toon et al. [1989] named it.

It is mainly for the latter reason that certain laboratories gathered within the "Antarctica 1992" project in order to use the whole set of measurements available at the French station of Dumont d'Urville $\left(67^{\circ} \mathrm{S}, 140^{\circ} \mathrm{E}\right)$, in conjunction with satellite measurements from August 14 to September 20, 1992. This site appears to be statistically at the edge of the vortex (either inside or outside) during the 1-month period considered. The initial project mainly consists in the determination of vertical and longitudinal structures of PSCs along with their type and formation mode, and in the quantification of $\mathrm{O}_{3}$ loss and partitioning within the chlorine family.

Instruments operating at the station are an ozone and aerosol lidar, together with a Système d'Analyse par Observation Zénithale (SAOZ) instrument, detecting integrated $\mathrm{O}_{3}$, sunrise and sunset integrated $\mathrm{NO}_{2}$, and ozone sondes (about 20-40 sondes per year). Satellite data sets mainly consist of temperature measurements, $\mathrm{O}_{3}, \mathrm{H}_{2} \mathrm{O}, \mathrm{HNO}_{3}$, and $\mathrm{ClO}$ mixing ratios given by the Microwave Limb Sounder (MLS) instrument aboard the Upper Atmosphere Research Satellite (UARS); $\mathrm{ClONO}_{2}$, $\mathrm{NO}_{2}, \mathrm{HNO}_{3}, \mathrm{CH}_{4}, \mathrm{~N}_{2} \mathrm{O}$ mixing ratios, and aerosol extinction coefficients provided by the Cryogenic Limb Array Etalon Spectrometer (CLAES) instrument aboard UARS; and column ozone measurements from the Total Ozone Mapping Spectrometer (TOMS) instrument aboard the NIMBUS 7 satellite. Potential vorticity fields are evaluated from the U.K. Meteorological Office (UKMO) and the European Centre for MediumRange Weather Forecasts (ECMWF) assimilated data sets; temperature fields at 50 and $30 \mathrm{hPa}$ are taken from ECMWF. Vertical profiles of UARS constituents have been selected at pressure levels from 46 to $1 \mathrm{hPa}$. Temporal evolution of all these constituent fields have been compared with calculations from the SLIMCAT threedimensional (3-D) model.

The whole data set used in the analysis (groundbased, sondes and satellite measurements, model and assimilated data) is presented in detail in section 2 . Time evolution of all the species are studied in section 3.
Section 4 deals with chemical loss and production rates within the vortex. Finally, the study of PSC occurrences over the station, and generally over Antarctica, is shown in section 5 .

\section{Data Sets}

\subsection{Measurements at Dumont d'Urville}

A variety of stratospheric ozone related measurements is carried out since 1988 at Dumont d'Urville: total ozone and $\mathrm{NO}_{2}$ with a SAOZ UV-visible spectrometer, ozone profiles with a lidar and ozonesondes, PSC with a lidar, and daily temperature sondes.

2.1.1. SAOZ. The SAOZ is a UV-visible diode array spectrometer designed for measuring ozone and $\mathrm{NO}_{2}$ by looking at the sunlight scattered at zenith during twilight between $86^{\circ}$ and $91^{\circ}$ solar zenith angle (SZA) [Pommereau and Goutail, 1988]. It is a 512 or 1024 diodes array, $1.2 \mathrm{~nm}$ resolution spectrometer in the $300-600 \mathrm{~nm}$ range. Ozone is measured in the visible Chappuis bands between 450 and $580 \mathrm{~nm}$, where the cross sections are known with an accuracy of $1 \%$ and independent of temperature. The advantage of the method compared to UV instruments is to allow the measurements to be carried out even in the winter when the Sun elevation is too small for reliable readings in the UV. Ozone and $\mathrm{NO}_{2}$ slant columns retrieved by least squares iterative fitting with the cross sections are converted into vertical column using a standard air mass factor (AMF). The SAOZ standard AMF calculated for high latitude $\left(60^{\circ} \mathrm{N}\right)$ during the winter period is 16.59 for $\mathrm{O}_{3}$ and 17.77 for $\mathrm{NO}_{2}$ at $90^{\circ} \mathrm{SZA}$. The error introduced by the use of this standard AMF at Dumont d'Urville has been investigated using ozone profiles measured by more than 150 ozonesondes launched there since 1990 . On average, the standard AMF is $3 \%$ smaller than that calculated from the sondes at this station with little seasonal dependence [Pommereau et al., 1996]. Ozone columns are therefore overestimated by the same factor. Overall, in the absence of volcanic aerosol in the stratosphere and white outs at the surface, the precision of the measurements is of $5 \mathrm{DU}$ for ozone (plus the above $+3 \%$ average systematic bias) and $3 \times 10^{14} \mathrm{~mol} \mathrm{~cm}^{-2}$ for $\mathrm{NO}_{2}$ (plus a systematic bias of $20 \%$ due to the use of cross sections measured at room temperature instead of at low temperature).

A potential perturbation of the zenith sky measurements from the ground is the presence of PSCs or dense volcanic aerosols [Sarkissian et al., 1994]. As shown later, PSCs were not detected at Dumont d'Urville during the period of interest. However, volcanic aerosols were still present in August 1992, 14 months after the eruption of Mount Pinatubo. The influence on the AMF of the aerosol loading has been calculated with a radiative transfer model from a zonal average of the aerosol profiles reported by Stratospheric Aerosol and Gas Experiment (SAGE) II. On average, during the AugustSeptember period, at latitudes greater than $55^{\circ} \mathrm{S}$, the 
ozone AMF would have been reduced by $8 \%$, which results in a systematic underestimation of the $\mathrm{SAOZ}$ ozone column by the same amount. However, this is not true in the vortex where sedimentation of the PSCs during the winter could have reduced the aerosol loading. Because of the large volcanic aerosol loading, the SAOZ total ozone measurements in 1992 must be taken with care. It is possible that aerosol fluctuations from one day to the other or from the inside to the outside of the vortex could lead to apparent variations in the SAOZ data of about $5 \%$. Note that since the altitude of the $\mathrm{NO}_{2}$ layer is above that of the aerosol, this does not apply to $\mathrm{NO}_{2}$ columns measured at twilight.

Another potential perturbation in Antarctica in general and at Dumont d'Urville in particular where the wind speed at sea level is the highest of the continent is the influence of multiple scattering during white out episodes. These could result (1) in large interferences in the spectra since the absorption by $\mathrm{H}_{2} \mathrm{O}$ and $\mathrm{O}_{4}$ (the oxygen collision complex) could be 5 to 10 times larger than that of ozone in the $450-580 \mathrm{~nm}$ spectral range; (2) in an enhancement of the tropospheric ozone contribution in the total ozone absorption since the ozone concentration in the lower levels is the largest during the winter. Indeed, a positive correlation between white outs and total ozone is present in the results. White out periods are identified by an enhancement of absorption by $\mathrm{O}_{4}$ by more than a factor of 5 compared to the average. This represents about 15-20 twilights per year, more frequent during the winter. Two large white out episodes have been reported during the 50 days of interest here: from August 15 in the evening to the following day in the evening and on the evening of September 8 to the following morning. The corresponding ozone measurements have been removed from the data set. In contrast, there is no evidence of correlation between $\mathrm{NO}_{2}$ and white outs which are thus not removed for this species. Another perturbation which occurs from time to time is the absence of light because of snow on the window of the instrument not removed early enough. This could generate some gaps in the data set and is difficult to avoid.

The ozone data shown are daily morning-evening mean at noon (about 0200 UT) or one of the two if one is missing, derived from twilight $\left(86^{\circ}-91^{\circ} \mathrm{SZA}\right)$ precision-weighted averages. For comparison purpose, it must be recalled that zenith sky measurements at $90^{\circ}$ correspond to light path averaging between the location of the station and $100 \mathrm{~km}$ in the direction of the Sun (roughly NE in the morning, NW in the evening in August-September).

2.1.2. Lidar. Lidar measurements of aerosol and polar stratospheric clouds (PSC) are carried out at Dumont d'Urville since 1989 in cooperation with the Italian Istituto di Recerca sulle Onde Electromagnetica (IROE). A multiwavelength lidar intended to measure the ozone profile was implemented in 1991 and operated permanently since then, except in the summer. This li- dar provides vertical profiles of ozone number density from 15 to $40 \mathrm{~km}$ and aerosol backscatter and extinction coefficients at 532 and $355 \mathrm{~nm}$ from 8 to $30 \mathrm{~km}$ [Stefanutti et al., 1992; Godin et al., 1994a, b]. However, as for $\mathrm{SAOZ}$, the lidar measurements were largely perturbed in the lower stratosphere by the volcanic aerosols in 1992, where the data were only reliable above $60 \mathrm{hPa}$. Seven ozone profiles from 60 to $8-10 \mathrm{hPa}$ are available during the period of interest, on August 27 and 31 and September $1,3,10,11$, and 19, while lidar aerosol data are available for 9 days, on August 25, 27, 28, and 31 and September 1, 3, 10, 11, and 19.

2.1.3. Ozonesondes. A program of regular 25-30 Electro-Chemical (ECC) sondes per year is also run at Dumont d'Urville providing profiles from the surface up to 8-20 hPa depending on the temperature-dependent burst altitude of the balloon. The results of seven ascents are available for the period under consideration on August 17, 21, and 31 and September 6, 10, 14, and 18.

\subsection{Satellite Measurements}

The UARS orbit has an inclination of $57^{\circ}$. Both CLAES and MLS instruments operate on the anti-Sun side of the spacecraft. Measurements can then cover a latitude band from $80^{\circ}$ on one side of the equator to $34^{\circ}$ on the other side. Since the UARS orbit plane precesses by about 20 min each day, the spacecraft is rotated $180^{\circ}$ about its yaw axis every 36 days. Thus high latitudes can only be observed roughly 1 month in every 2 . During the 1992 southern hemisphere winter period, MLS [Waters, 1993; Barath et al., 1993] and CLAES [Roche et al., 1993] observations were simultaneous and colocated from August 16 to September 15, 1992. Furthermore, the Halogen Occultation Experiment (HALOE) instrument [Russell et al., 1993] uses solar occultation technique and enables the detection of various interesting species such as $\mathrm{HCl}$, but observations only reached high latitudes by the end of September 1992. Thus HALOE measurements are not included in the UARS data set.

2.2.1. UARS/MLS. MLS measurements of $\mathrm{O}_{3}$, $\mathrm{ClO}, \mathrm{HNO}_{3}$, and temperature made with the 205-GHz radiometer, and $\mathrm{H}_{2} \mathrm{O}$ made with the $183-\mathrm{GHz}$ radiometer, have been selected from August 14 to September 20,1992 , at different pressure levels: $46,21,10,4.6$, 2.1 , and $1 \mathrm{hPa}$. We also used $\mathrm{H}_{2} \mathrm{O}$ estimated by a nonlinear process performed at Edinburgh University. Data used are time-interpolated and stored in level 3AT files labeled Version 4 in the Central Data Handling Facility (CDHF). Only measurements recorded (1) within a box of $5^{\circ}$ in latitude and $15^{\circ}$ in longitude of Dumont d'Urville and (2) with a positive uncertainty, that is, with an a priori contribution less than $25 \%$, were taken. During the whole period, $\mathrm{O}_{3}, \mathrm{H}_{2} \mathrm{O}, \mathrm{HNO}_{3}$, and temperature fields have been diurnally averaged over the selected area, whereas for $\mathrm{ClO}$, only daytime measure- 
ments were taken. Vertical profiles of constituents are given in mixing ratio. The vertical resolution of UARS MLS measurements is about $5 \mathrm{~km}$.

2.2.2. UARS/CLAES. CLAES measurements, selected from August 16 to September 15, 1992, are $\mathrm{CH}_{4}, \mathrm{HNO}_{3}, \mathrm{NO}_{2}, \mathrm{ClONO}_{2}, \mathrm{~N}_{2} \mathrm{O}$, and extinction coefficients of aerosols at $780 \mathrm{~cm}^{-1}$ (blocker $9,12.82 \mu \mathrm{m}$ ) for different pressure levels $46,21,10,4.6,2.1$, and $1 \mathrm{hPa}$. Data used are time-interpolated and stored in level 3AT files labeled Version 7 in the CDHF for $\mathrm{ClONO}_{2}, \mathrm{CH}_{4}$, and $\mathrm{NO}_{2}$, and Version 8 for the remaining constituents. The complete validation of CLAES Version $7 \mathrm{NO}_{2}$ retrievals has not been undertaken at this time largely because there are known deficiencies that are likely to be mitigated in future versions. As for MLS measurements, only data recorded within a box of $5^{\circ}$ in latitude and $15^{\circ}$ in longitude of Dumont d'Urville have been selected. During the whole period, these data have been averaged regardless of their local time of measurements, except for $\mathrm{ClONO}_{2}$ and $\mathrm{NO}_{2}$ for which either daytime or nighttime profiles have been taken. Vertical profiles of constituents are given in mixing ratio. The vertical resolution of UARS CLAES measurements is about $2.5 \mathrm{~km}$. Only data with an uncertainty less than the retrieval have been used.

2.2.3. TOMS. Total ozone measurements were also available in 1992 from the Total Ozone Mapping Spectrometer (TOMS) on board the NASA Nimbus 7 satellite. Those used here are daily overpass data over the Dumont d'Urville station processed with the algorithm version 7 .

\subsection{Meteorological Data}

Potential vorticity (PV) fields at the potential temperature $(\theta)$ of $475 \mathrm{~K}$ are provided by the ECMWF analysis at $1200 \mathrm{UT}$, while the PV fields at $495 \mathrm{~K}$ and $840 \mathrm{~K}$ have been derived from the UKMO assimilated data for the period August 14 to September 20, 1992. The 475-K isentropic layer is representative of the lowermost stratosphere and is used in conjunction with total column analysis. The $495-\mathrm{K}$ and $840-\mathrm{K} \theta$ layers correspond to the low stratospheric layer $(46 \mathrm{hPa})$ and to the midstratospheric layer ( $4.6 \mathrm{hPa}$ ) above the Dumont d'Urville station, respectively. Temperature fields at 50 and $30 \mathrm{hPa}$ provided by the ECMWF analysis at 1200 UT are also used.

Because the station is very often located at the edge of the vortex, a crude average of measurements performed within a box of $5^{\circ}$ in latitude and $15^{\circ}$ in longitude of the station is not appropriate for species which have a strong gradient at the vortex edge, which is the case for $\mathrm{ClO}$ and $\mathrm{HNO}_{3}$. In order to take into account this gradient effect, we have associated a PV value to each satellite data. Within this $5^{\circ} \times 15^{\circ}$ box, each profile has been weight-averaged with a weight dependent on (1) the difference $\Delta P V_{i}=P V_{i}-P V_{0}$ between the $P V$ value at the UARS measurement location $\left(P V_{i}\right)$ and the PV value at the station (PV $)$ and (2) the UARS measurement error variance $\sigma_{i}^{2}$. To avoid any singularity when $\Delta \mathrm{PV}_{i}$ is close to zero, we defined a weight as $\omega_{i}=\left(N / \sigma_{i}^{2}\right) \exp \left(-\Delta \mathrm{PV}_{i}^{2} / \Delta \mathrm{PV}_{0}^{2}\right)$, where $\Delta \mathrm{PV}_{0}$ is the mean in $\Delta \mathrm{PV}_{i}$ and $N$ is the normalization constant.

\subsection{SLIMCAT Model}

The SLIMCAT off-line three-dimensional chemical transport model (CTM) [Chipperfield et al., 1996] uses meteorological analyses to specify the horizontal winds and temperatures, while the vertical transport is diagnosed from calculated heating rates. The model contains a detailed treatment of stratospheric chemistry, including all of the species of interest described above, and has a treatment of heterogeneous reactions on PSCs and aerosols. For the experiments used here, the model was forced using UKMO analyses with a horizontal resolution of $3.75^{\circ} \times 3.75^{\circ}$ on 12 isentropic surfaces from 335 $\mathrm{K}$ to $2700 \mathrm{~K}$. The simulation was initialized on August 2,1992 , using output from a lower-resolution run initialized on October 21, 1991, and integrated until September 20, 1992. The 3-D model sulphate aerosol loading was specified from two-dimensional model calculations. The model global chemical fields were saved every 24 hours at 1200 UT. Output for Dumont d'Urville was obtained by interpolating from the nearest model gridpoints. For comparison with UARS data sets, the 1200 UT output for Dumont d'Urville was used to initialize a one-dimensional version of the model chemical module which was integrated over a diurnal cycle with a 5-min time step. Values closest to the UARS LST were then selected and interpolated onto the UARS pressure grid. For the comparison of column $\mathrm{O}_{3}$, a tropospheric contribution was added to the SLIMCAT data by assuming a volume mixing ratio of 25 ppbv between the surface and the bottom model level. Finally, Table 1 gives a list of instruments and species, with associated altitude ranges and with the available dates used in the present analysis.

\section{Time Evolution}

\subsection{Total Columns}

The time evolution of potential vorticity (PV), temperature, total ozone, and sunrise and sunset $\mathrm{NO}_{2}$ columns over Dumont d'Urville from August 13 to September 22 is displayed in Figure $1 .|\mathrm{PV}|$ at $475 \mathrm{~K}$ and temperature at 50 and $30 \mathrm{hPa}$ are those of the ECMWF analysis at $1200 \mathrm{UT}$, while the $\mathrm{O}_{3}$ columns together with the $50 \mathrm{hPa}$ temperature of the radiosondes correspond to daytime values around 1200 local noon (0200 UT). The SLIMCAT ozone column is at $1200 \mathrm{UT}$. The large amplitude variation of $|\mathrm{PV}|$ (Figure la) is the signature of the rotation of the vortex over Antarctica, the Dumont d'Urville station being located near the edge on average. If a limit of 45 PVU ( 1 PVU $=10^{-6} \mathrm{~K}$ $\mathrm{m}^{2} \mathrm{~kg}^{-1} \mathrm{~s}^{-1}$ ) is chosen for defining the inner vortex, 
Table 1. Database Used in the Analysis of the Stratosphere over Dumont d'Urville

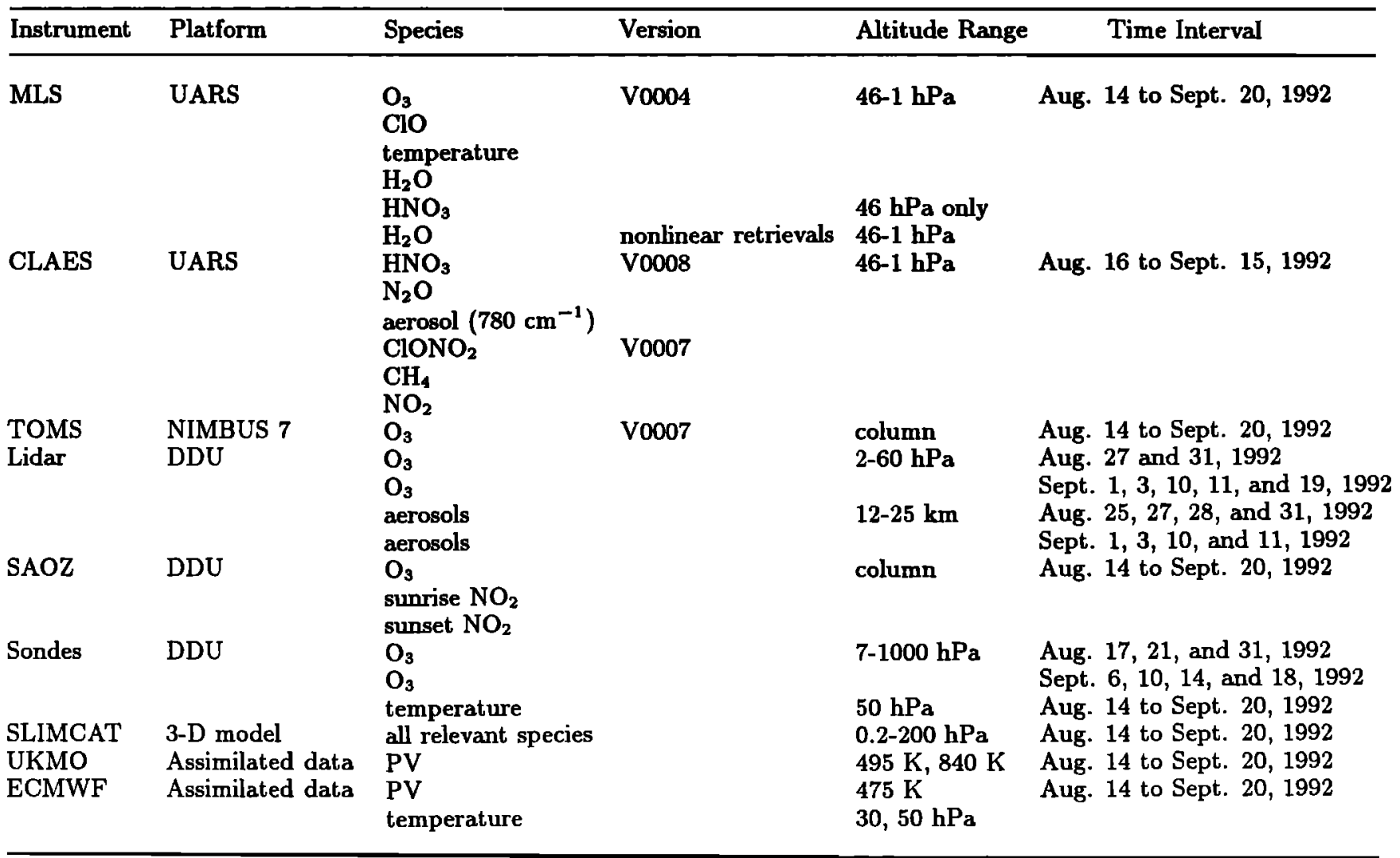

DDU, Dumont d'Urville.

the station is in the vortex during three long periods: August 18-23, August 29 to September 2, and September 17-20; and three shorter periods: August 26 and September 8 and 12 . At the opposite, the station is totally outside the vortex ( $|\mathrm{PV}|<36$ PVU) on August 13-15, September 7, 9-10, 14-15, and on September 22. Between these periods, the station is at the edge of the polar vortex.

Compared to that prevailing at that season over Western Antarctica, stratospheric temperatures (Figure 1b) are relatively warm over the station, always above 200 $\mathrm{K}$ that is above that of formation of PSC. The $30 \mathrm{hPa}$ level is always warmer than the $50 \mathrm{hPa}$, by 5 to $15 \mathrm{~K}$. The modeled temperature at $50 \mathrm{hPa}$ at $1200 \mathrm{UT}$ is in excellent agreement with that measured by radiosonde at 0200 UT shifted by 10 hours. This agreement is not a surprise since the station is the only WMO station available in the area, and therefore the model is strongly weighted by its reports. Large warmings at $30 \mathrm{hPa}$ up to $240 \mathrm{~K}$ are observed when the vortex is distant from the station in September.

The three ozone columns (SAOZ, TOMS, and SLIM$\mathrm{CAT})$ track each other in anticorrelation with $|\mathrm{PV}|$ displaying variations of $200 \mathrm{DU}$ amplitude associated with the motion of the vortex (Figure 1c). The anticorrelation between total ozone and $|\mathrm{PV}|$ is higher for SLIMCAT $(|r|=0.78)$ than for the two instruments $(|r|=$
0.67 and 0.68 for SAOZ and TOMS, respectively). This is not surprising since the dynamics in the photochemical model is prescribed with the UKMO model at 1200 UT, while the two daytime measurements are shifted by approximately $\mathbf{1 0}$ hours. Since diabatic subsidence would result in a relative ozone increase in the vortex compared to the outside [Roscoe et al., 1997], it is clear that large photochemical losses have occurred within. From the beginning until the end of the period of $\mathbf{5 0}$ days, the total ozone drop at constant PV is of the order of 80-100 DU. TOMS and SAOZ correlate very well $(r=0.88)$, although the total ozone reported by TOMS is larger than that of SAOZ in September outside as well as inside the vortex. The seasonal increase of the difference between TOMS and SAOZ at spring is a permanent feature of the comparison between the two instruments, sought to be related to the influence of the ozone profile shape in the TOMS retrieval algorithm [Pommereau et al., 1996]. The correlation of the two measurements with SLIMCAT is also very high (0.76 and 0.87 for SAOZ and TOMS, respectively). However, a closer look at the plot shows that the simulated column in the vortex at constant PV is the lowest in August and the highest by the end of September, suggesting that SLIMCAT could underestimate the loss during the 2 month period by some $30 \mathrm{DU}$.

In contrast, $\mathrm{NO}_{2}$ is little correlated with the motion of 


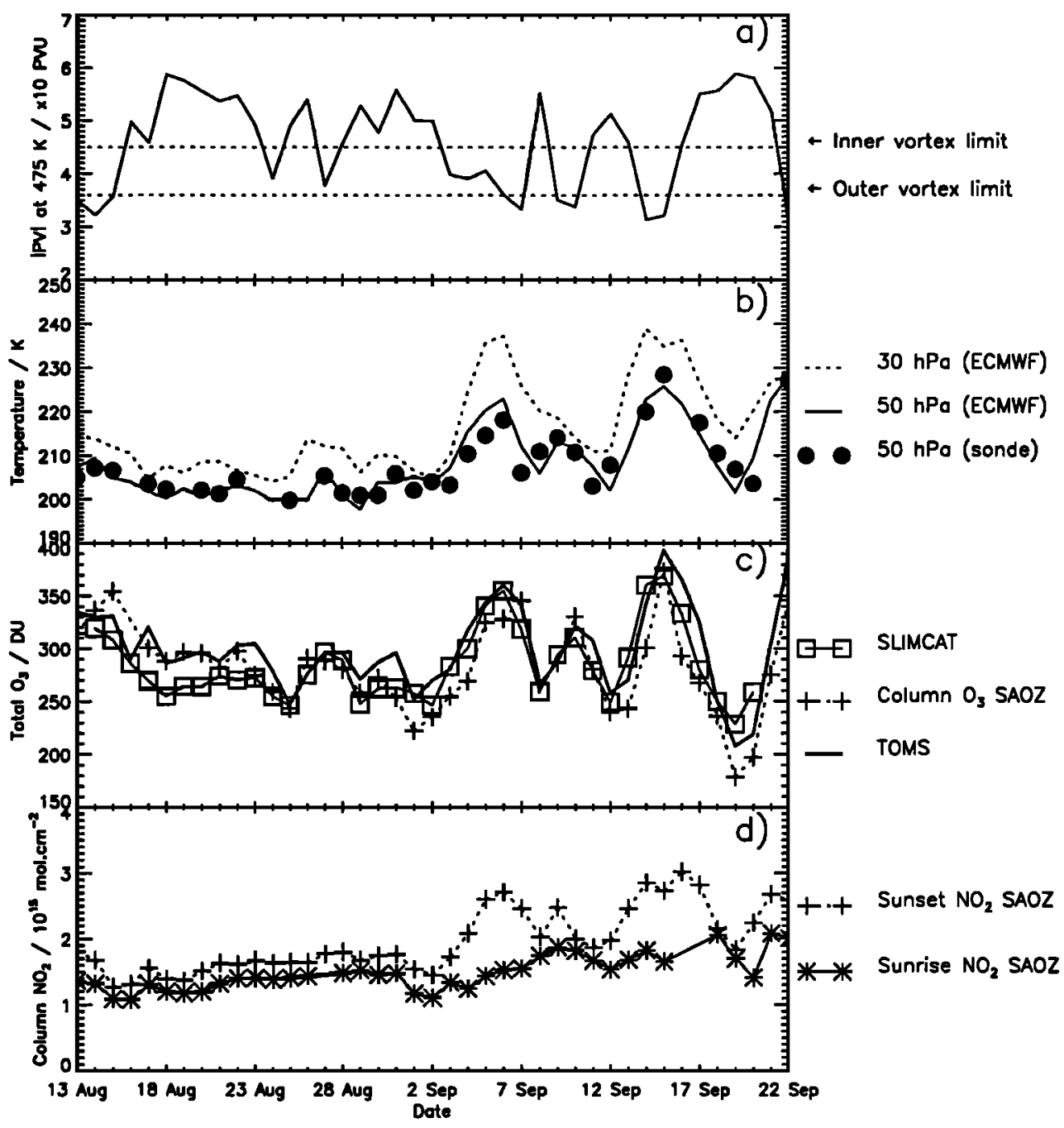

Figure 1. Time series of (a) the potential vorticity $|\mathrm{PV}|$ at $475 \mathrm{~K}$ calculated from the ECMWF assimilated data set, (b) temperature at $50 \mathrm{hPa}$ (solid line) and $30 \mathrm{hPa}$ (dotted line) from the ECMWF assimilated data set and from radiosondes (solid circles) at $50 \mathrm{hPa}$, (c) total $\mathrm{O}_{3}$ as measured by SAOZ (plusses), TOMS (thick line) and calculated by SLIMCAT (squares), and (d) total sunset (plusses) and sunrise (asterisks) $\mathrm{NO}_{2}$ as measured by $\mathrm{SAOZ}$ from August 14 to September 20,1992, over the Dumont d'Urville station. The two horizontal dotted lines in the upper panel represent the inner and the outer vortex limits set to 45 and 36 PVU, respectively.

the vortex (Figure 1d), but strongly in the evening with temperature as already known [Pommereau and Goutail, 1988; Goutail et al., 1994; Kondo et al., 1994]. Consequently, the column is significantly larger $\left(1.4 \times 10^{15}\right.$ $\mathrm{mol} \mathrm{cm}{ }^{-2}$ ) in the morning in August at $200-210 \mathrm{~K}$ over the Dumont d'Urville station than over the Syowa station $\left(69^{\circ} \mathrm{S}, 40^{\circ} \mathrm{E}\right)\left(0.5 \times 10^{15} \mathrm{~mol} \mathrm{~cm}{ }^{-2}\right)$ at the same time but at $190 \mathrm{~K}$ [Kondo et al., 1994]. Similar low $\mathrm{NO}_{2}$ columns were also observed at the Dumont d'Urville station in 1992 but before July 15, only before the temperature increased by $20 \mathrm{~K}$ within a few days. In addition, as also observed in the Arctic during the winter [Goutail et al., 1994], the amplitude of the column at equivalent temperature was reduced by $40 \%$ in 1992 compared to other years after the heterogeneous conversion of $\mathrm{NO}_{x}$ into $\mathrm{HNO}_{3}$ onto the volcanic aerosol in the lower stratosphere.
The morning column shows little modulation during the 2 months. In contrast, the evening column and therefore the amplitude of the diurnal cycle are highly correlated with temperature and the position relative to the vortex. The amplitude of the diurnal variation is the largest when the station is located away from the vortex. It almost vanishes inside. The behavior of the $\mathrm{NO}_{2}$ column during the winter is very similar in the Antarctic and in the Arctic [Goutail et al., 1994]. The evolution of vertical distribution of the concentration of the species has been explored by series of balloon flights in the Arctic in 1992 [Pommereau and Piquard, 1994] which have been interpreted using a Lagrangian model [Lateltin et al., 1994]. At sunrise, most of $\mathrm{NO}_{2}$ is located above 22-23 km, where the heterogeneous conversion of $\mathrm{NO}_{x}$ into $\mathrm{HNO}_{3}$ on PSC is not operative since there is no PSC. Therefore there is little difference between 
the columns inside and outside the vortex or maybe a little larger amount inside because of the subsidence of $\mathrm{NO}_{y}$ as could be seen on Figure 1d. During daytime, $\mathrm{NO}_{2}$ increases after the photolysis of $\mathrm{N}_{2} \mathrm{O}_{5}$ in the lower stratosphere, but mostly below $23 \mathrm{~km}$. The process is efficient outside the vortex where the total $\mathrm{NO}_{x}$ concentration is relatively large after the photolysis of $\mathrm{HNO}_{3}$, but not inside where denoxification (conversion of $\mathrm{NO}_{x}$ into $\mathrm{HNO}_{3}$ ) in the Arctic and, in addition, denitrification (removal by sedimentation of $\mathrm{HNO}_{3}$ absorbed in the PSC particles) in the Antarctic, have depleted most of the $\mathrm{NO}_{x}$. The diurnal cycle then vanishes.

On average, the $\mathrm{NO}_{2}$ column increases during the 2 months. However, the rate of increase during the $\mathbf{5 0}$ days is lower (40\%) in the morning (inside and outside the vortex) and in the evening inside the vortex than outside the vortex in the evening (90\%). The cause of the seasonal increase outside the vortex in the evening is the increase of $\mathrm{NO}_{x}$ after the slow photolysis of $\mathrm{HNO}_{3}$. The explanation of the different rate of increase comes from the amount of $\mathrm{HNO}_{3}$ available: large outside the vortex in the lower stratosphere, but limited elsewhere, that is, everywhere at high altitude and within the vortex at low altitude. Consequently, the fastest increase is observed outside the vortex at low altitude in the evening data.

The rate of increase of $\mathrm{NO}_{2}$ and the location and altitude where it takes place is important since $\mathrm{NO}_{2}$ could react with $\mathrm{ClO}$ to form $\mathrm{ClONO}_{2}$ and thus deactivate chlorine and stop the ozone loss process as that will be discussed later. From the $\mathrm{NO}_{2}$ data shown, it can be concluded that little deactivation occurred in the lower stratosphere in the vortex in August-September, but in contrast, $\mathrm{ClONO}_{2}$ could have formed rapidly in the lower stratophere at the edge of the vortex, in the "collar" region where high $\mathrm{ClONO}_{2}$ amount is observed at spring.

\subsection{Vertical Profiles}

Figures 2 and 3 show the temporal evolution of MLS, CLAES, and SLIMCAT data from August 14 to September 20,1992 , at 46 and $4.6 \mathrm{hPa}$, respectively. The 46 $\mathrm{hPa}$ layer was chosen to be representative of the lower stratospheric processes that affect chemically perturbed regions (e.g., chlorine and PSC activation), while the 4.6 $\mathrm{hPa}$ layer is more representative of the middle stratosphere. Time series shown in Figures 2 and 3 include potential vorticity calculated from the UKMO assimilated data set, daytime solar zenith angle, daytime local solar time, temperature, potential temperature, daytime $\mathrm{ClO}, \mathrm{O}_{3}$, aerosol extinction coefficients from CLAES, $\mathrm{H}_{2} \mathrm{SO}_{4}$ from SLIMCAT, $\mathrm{HNO}_{3}$ from CLAES, $\mathrm{H}_{2} \mathrm{O}$ from MLS V4 and a nonlinear retrieval analysis performed at Edinburgh University, $\mathrm{N}_{2} \mathrm{O}, \mathrm{CH}_{4}$, daytime $\mathrm{ClONO}_{2}$, and daytime $\mathrm{NO}_{2}$. Estimated $\mathrm{ClO}_{x}\left(=\mathrm{ClO}+2 \mathrm{Cl}_{2} \mathrm{O}_{2}\right)$ at 46 and $4.6 \mathrm{hPa}$ are represented together with $\mathrm{ClO}$ in Figures $2 \mathrm{f}$ and $3 \mathrm{f}$, respectively. At $46 \mathrm{hPa}$, sonde and lidar ozone measurements are also represented (Figure
$2 \mathrm{~g}$ ) together with aerosol lidar measurements (Figure 2h). $\mathrm{MLS} \mathrm{HNO}_{3}$ is only represented at $46 \mathrm{hPa}$ (Figure 2j).

At both levels, temperature tends to increase over the whole period except at $46 \mathrm{hPa}$, where it slightly decreases at the beginning of the period. The agreement between MLS and the UKMO analyses used to force SLIMCAT is very good at $4.6 \mathrm{hPa}$, but at $46 \mathrm{hPa}$, MLS measurements are greater than the UKMO analyses by about $10 \mathrm{~K}$. The displacement of the vortex away from the station is associated with an increase in the temperature field. Indeed, potential temperatures at isobaric levels appear to be stable except during these events when they obviously increase, corresponding to air parcels that are representative of outer vortex areas at upper levels.

At $46 \mathrm{hPa}$, MLS daytime $\mathrm{ClO}$ is clearly activated with values greater than 0.5 ppbv during the periods August 16-26, August 28 to September 4, and September 8,12 , and 19 in rather good coincidence with vortex crossings. Indeed, the correlation coefficient between $|\mathrm{PV}|$ and MLS daytime ClO is $r=0.66$. Furthermore, the anticorrelation between $\mathrm{ClO}$ and temperature at $46 \mathrm{hPa}$ is quite large, reaching $|r|=0.76$, while it is completely negligible between $\mathrm{ClO}$ and $\mathrm{O}_{3}: r=0.04$. Chlorine monoxide computed by SLIMCAT at the same LST as UARS measurements behaves qualitatively well compared to MLS daytime ClO measurements but is quantitatively much less than MLS in August. A maximum of $\sim 2 \mathrm{ppbv}$ of ClO is observed by MLS, while SLIMCAT calculates only $0.6 \mathrm{ppbv}$ for the same period around August 20, 1992. Later in the comparison period, after September 4, the agreement is better. The maximum MLS inner-vortex $\mathrm{ClO}$ is about $2 \mathrm{ppbv}$ during the first part of the 1-month period before September 8 , and less than $1 \mathrm{ppbv}$ afterward. This negative trend is well correlated with a positive temperature evolution that starts below $200 \mathrm{~K}$ at the beginning of the period and reaches around $205 \mathrm{~K}$ at the end. This decreases the probability of polar stratospheric cloud formation. At $4.6 \mathrm{hPa}$ (Figure 3f), although the MLS retrievals are more noisy, a stratospheric ClO maximum of $\sim 0.5 \mathrm{ppbv}$ as measured by MLS is also reproduced by SLIMCAT.

The quantitative behavior of MLS ClO in the Antarctic lower stratosphere has been studied previously. Chipperfield et al. [1996] and Santee et al. [1996] used a version of the SLIMCAT model at a slightly higher horizontal resolution $\left(2.8^{\circ} \times 2.8^{\circ}\right)$ to investigate the decay of the inner and edge vortex-averaged MLS $\mathrm{ClO}$ at 465 $\mathrm{K}$ in the Antarctic in September 1992. In their short study, the model was initialized using UARS data on August 31, 1992, and integrated for 32 days. Chipperfield et al. [1996] found that at $465 \mathrm{~K}$ the model underestimated the observed $\mathrm{ClO}$ in the vortex center: in early September, the average inner vortex MLS ClO was around $1.9 \mathrm{ppbv}$, compared with $1.4-1.5 \mathrm{ppbv}$ in the model. This discrepancy was not due to an underestimate of the chlorine activation, but probably due to 


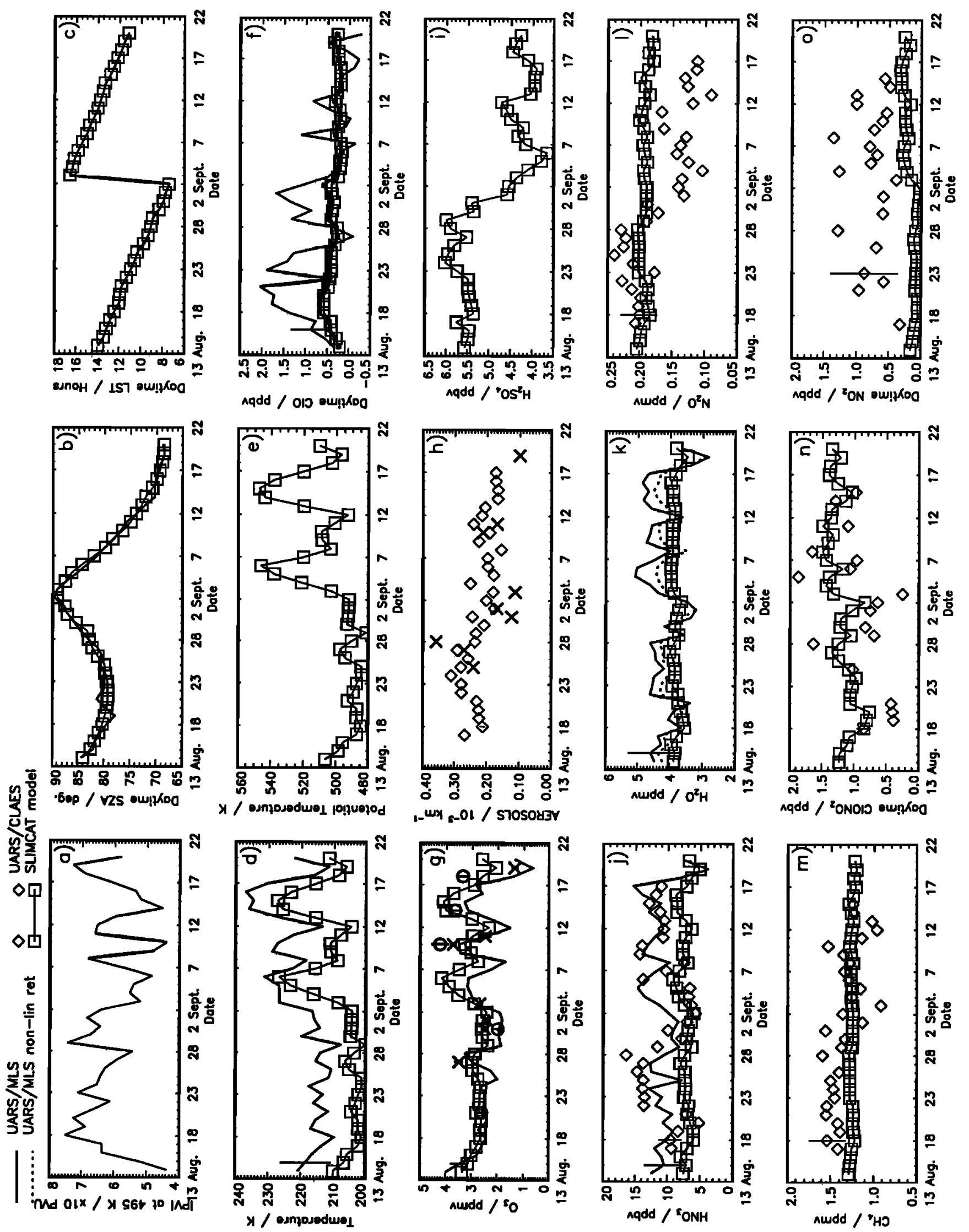

Figure 2. 
a problem in the partitioning of $\mathrm{ClO}$ and $\mathrm{Cl}_{2} \mathrm{O}_{2}$; that is, the model partitioned too much $\mathrm{ClO}_{x}$ into $\mathrm{Cl}_{2} \mathrm{O}_{2}$ to reproduce the very high $\mathrm{ClO}$ observations. At the vortex edge, Chipperfield et al. [1996] found a much better agreement between the average MLS ClO observations and the model which were both around $0.8 \mathrm{ppbv}$. The quantitative disagreement between the SLIMCAT and MLS $\mathrm{ClO}$ in Figure 2f occurs before September 1 and the period of the Chipperfield et al. [1996] study. By considering vortex edge averages, Chipperfield et al. [1996] removed the large day-to-day variations seen in the single site comparison shown here, so their good comparison is similar to our study in this later period. Concerning the discrepancy in August, in our study the degree of chlorine activation is generated within the CTM on the basis of the specified meteorological analyses. Figure 2f also shows the $\mathrm{ClO}_{x}$ field from the CTM run. This shows that the model underestimate of the $\mathrm{ClO}$ observations in August is not due to significant active chlorine being partitioned into $\mathrm{Cl}_{2} \mathrm{O}_{2}$. Rather, it is the degree of activation which is underestimated in the model, although the model would not be able to reproduce the highest observed mixing ratios of $2 \mathrm{ppbv}$, even with complete activation of chlorine (see inner vortex discussion of Chipperfield et al. [1996]). Therefore part of the ClO discrepancy in August is related to the modest model resolution and the location of Dumont d'Urville at the edge of the vortex. The model does activate $\mathrm{ClO}_{x}$ strongly within the polar vortex; for example, the maximum model mixing ratio of $\mathrm{ClO}_{x}$ at $480 \mathrm{~K}$ is $2.5 \mathrm{ppbv}$, which yields around $1.3 \mathrm{ppbv}$ of $\mathrm{ClO}$ in sunlight at this altitude. However, at the vortex edge, the model resolution cannot maintain the strong gradients in species such as $\mathrm{ClO}_{x}$. Indeed, comparison of other long-lived tracers (e.g., $\mathrm{N}_{2} \mathrm{O}, \mathrm{CH}_{4}$ ) shows

Figure 2. Time series of (a) the potential vorticity $|\mathrm{PV}|$ at $495 \mathrm{~K}$ calculated from the UKMO assimilated data set, (b) daytime solar zenith angle (degree), (c) daytime local solar time (hours), (d) temperature, (e) potential temperature, (f) daytime $\mathrm{ClO}$, (g) $\mathrm{O}_{3}$, (h) aerosol extinction coefficients $\left(10^{-3} \mathrm{~km}^{-1}\right)$, (i) $\mathrm{H}_{2} \mathrm{SO}_{4}$, (j) $\mathrm{HNO}_{3}$, (k) $\mathrm{H}_{2} \mathrm{O}$ (solid lines, while dotted lines represent nonlinear process), (l) $\mathrm{N}_{2} \mathrm{O}$, (m) $\mathrm{CH}_{4}$, (n) daytime $\mathrm{ClONO}_{2}$ and (o) daytime $\mathrm{NO}_{2}$ from UARS/MLS (thick lines), UARS/CLAES (diamonds) measurements and SLIMCAT model (squares) at $46 \mathrm{hPa}$ from August 14 to September 20, 1992, above the Dumont d'Urville station. Estimated $\mathrm{ClO}_{x}\left(=\mathrm{ClO}+2 \mathrm{Cl}_{2} \mathrm{O}_{2}\right)$ is represented by a tiny thick square in Figure 2f. Sonde and lidar ozone measurements averaged from 40 to 50 $\mathrm{hPa}$ are represented by an open circle and a cross, respectively, in Figure 2g. Aerosol extinction coefficients $\left(10^{-2} \mathrm{~km}^{-1}\right)$ as measured by the lidar instrument within the range $40-50 \mathrm{hPa}$ are represented by crosses in Figure 2h. Vertical bars represent the 1- $\sigma$ error on the measurements. that SLIMCAT does not follow the detailed evolution of these tracers as the vortex moves over the station.

Ozone temporal evolutions as measured by MLS, lidar, and sondes, and as deduced from SLIMCAT, are broadly well correlated except that the negative trend in the $\mathrm{O}_{3}$ field at $46 \mathrm{hPa}$ is not well reproduced by the SLIMCAT model, which is probably related to the model underestimate of ClO. Indeed, a negative trend in the MLS $\mathrm{O}_{3}$ field can be noted during the whole period of this study, starting from 4 ppmv and reaching about 1 ppmv on September 20. Although at the beginning of the period, SLIMCAT and MLS $\mathrm{O}_{3}$ fields compare well, at the end of the period, SLIMCAT estimates much more ozone ( $\sim 2$ ppmv) than observed by MLS ( 1 ppmv). Figure 4 shows, when available, $\mathrm{O}_{3}$ vertical profiles measured by lidar, sonde, and MLS, and calculated by SLIMCAT on August 17, 21, 27, and 31 and on September 1, 3, 6, 10, 11, 14, 18, and 19, 1992. Over the whole intercomparison period, there is a good agreement between all measured data sets except on September 10, 1992, when this date is associated with a very rapid change in $P V$, explaining the strong variability in the $\mathrm{O}_{3}$ vertical profiles with less convincing agreements. At $46 \mathrm{hPa}$, for inner-vortex periods, $\mathrm{O}_{3}$ calculated by SLIMCAT tends to be larger than MLS, lidar, and sonde. Around $20 \mathrm{hPa}$, whatever the inneror outer-vortex period considered, SLIMCAT systematically overestimates the $\mathrm{O}_{3}$ amount corresponding to all data sets. Once again, as for ClO, it may be that SLIM$\mathrm{CAT} \mathrm{O}_{3}$ does not behave too well for stations located too close to the vortex edge, because of the model horizontal resolution. At $4.6 \mathrm{hPa}$, both MLS and SLIMCAT ozone fields track the same atmosphere, but SLIMCAT systematically underestimates $\mathrm{O}_{3}$ by about 1-1.5 ppmv as compared to MLS.

The temporal evolution of the aerosol extinction coefficients as measured by CLAES at $46 \mathrm{hPa}$ is in good qualitative agreement with the SLIMCAT $\mathrm{H}_{2} \mathrm{SO}_{4}$ field. No real peak of aerosol extinction coefficients can be seen during the whole period at this pressure level indicating the absence of PSC events, consistent with the above analysis of the temperature field. This assertion is confirmed by lidar measurements of aerosol extinction coefficients performed during the winter 1992 at Dumont d'Urville. Indeed, during this period, there is no strong signal at heights above $18 \mathrm{~km}$. It is nevertheless interesting to note a negative trend both in the aerosol extinction coefficients, as measured by the lidar and CLAES instruments, and in the model $\mathrm{H}_{2} \mathrm{SO}_{4}$ field over the whole period, indicating subsidence effect inside the vortex. At $4.6 \mathrm{hPa}$, CLAES aerosol data are too sparse to infer any conclusion.

At $46 \mathrm{hPa}$, SLIMCAT, UARS/MLS, and UARS/CLAES produce $\mathrm{HNO}_{3}$ fields that qualitatively compare well with less $\mathrm{HNO}_{3}$ inside the vortex than outside. However, outer-vortex UARS data are larger than SLIM- 

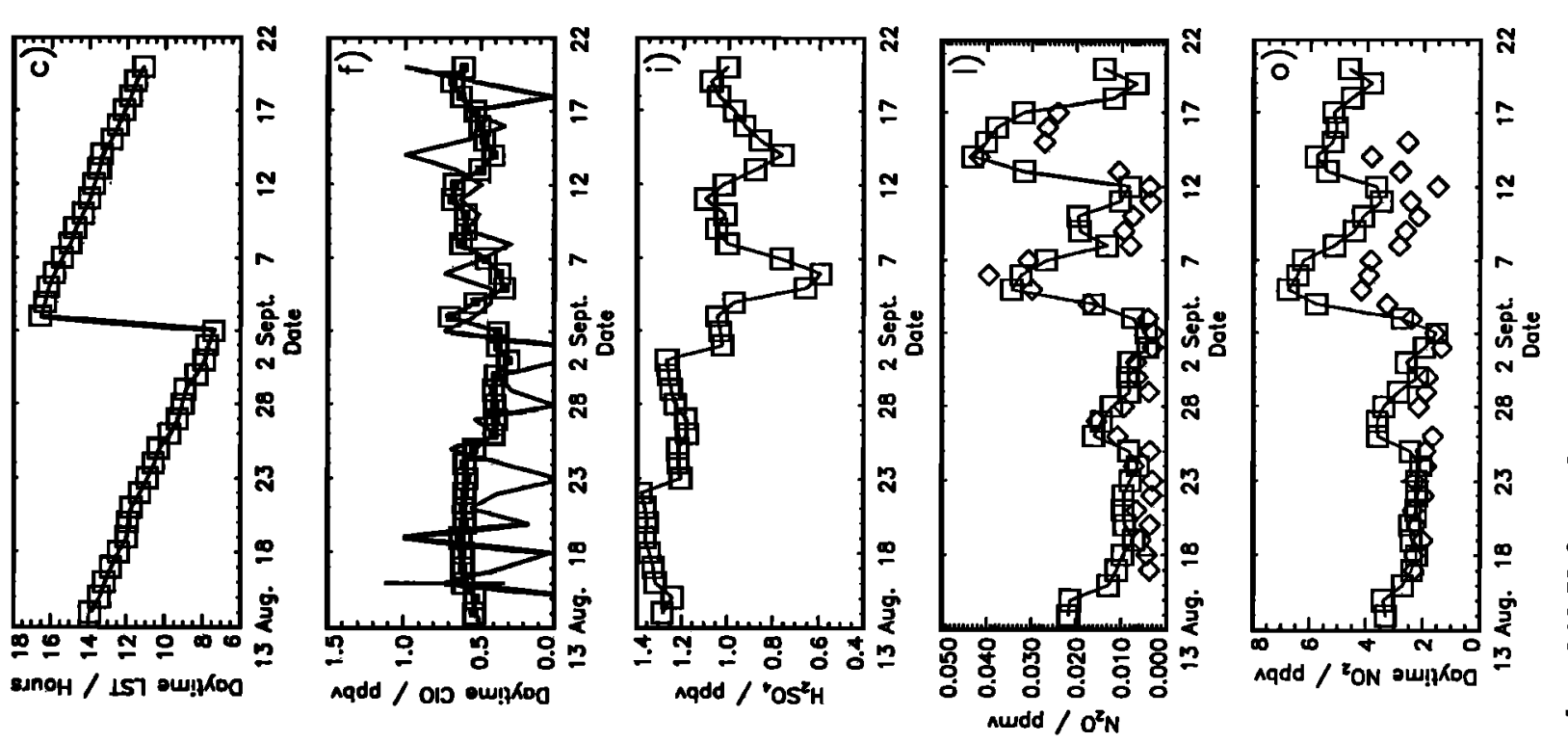

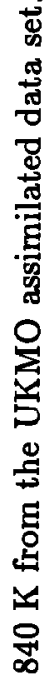
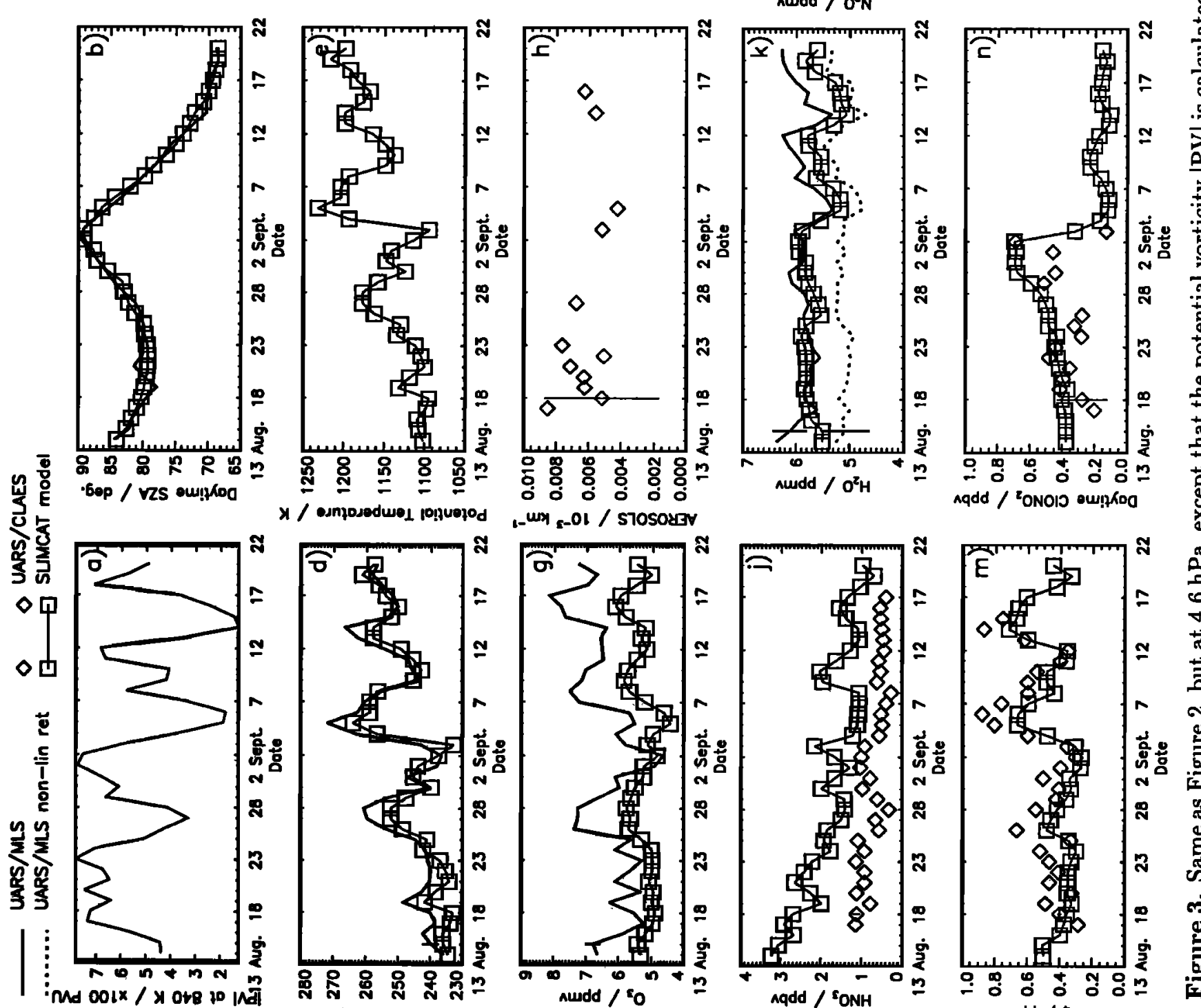

$$
\text { เ-WXy r-01 / S70sorar }
$$

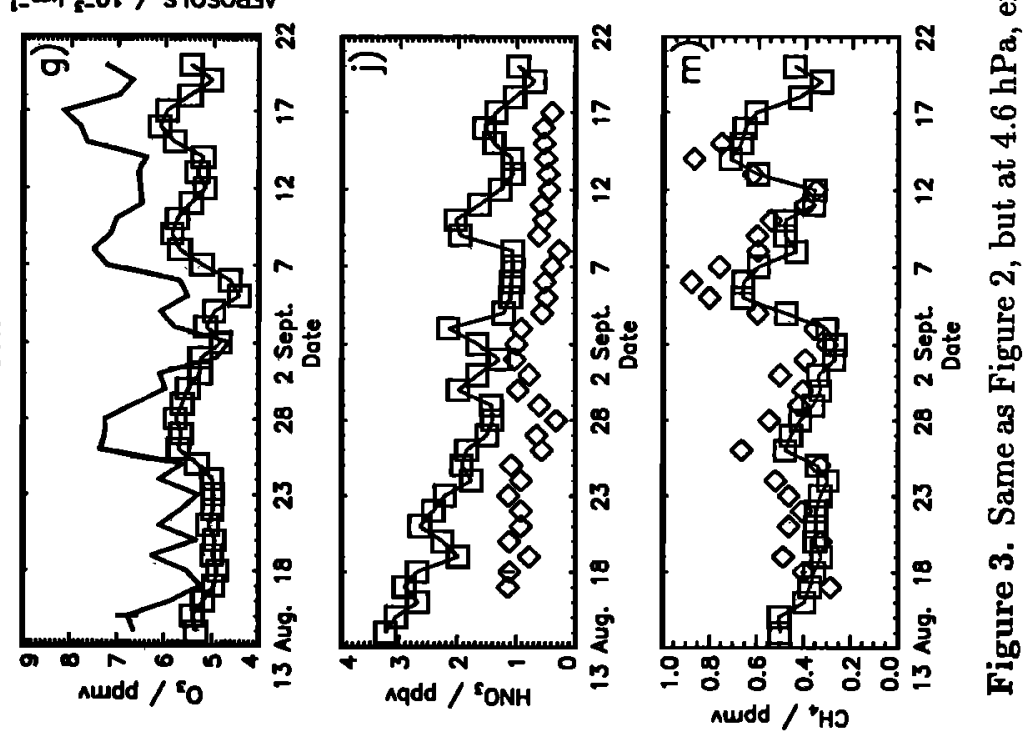



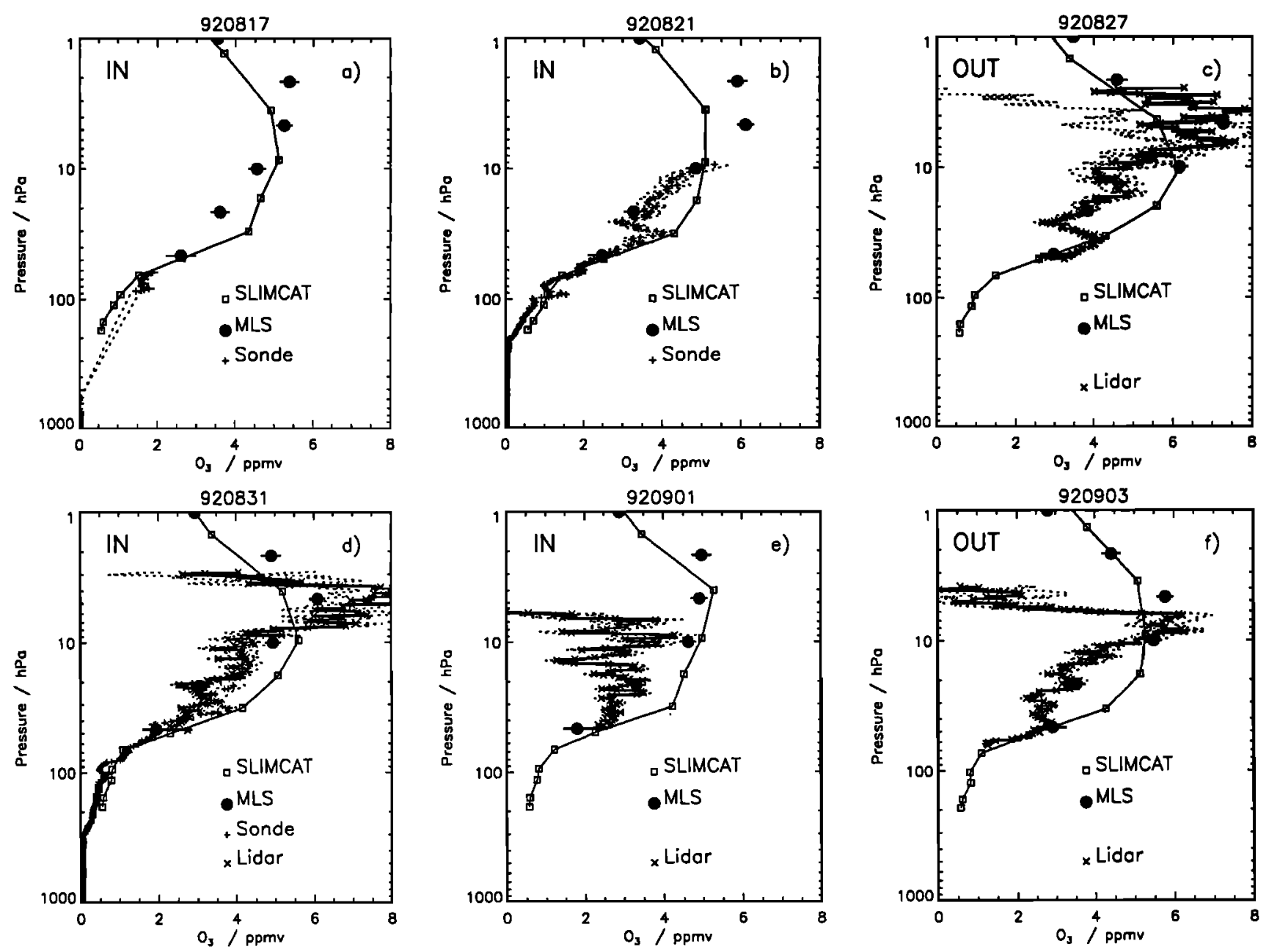

Figure 4. Ozone vertical profiles as measured by MLS (solid circles), lidar (crosses), sondes (plusses), and as calculated by SLIMCAT (squares) on (a) August 17, (b) 21, (c) 27, and (d) 31 and on (e) September 1, (f) 3, (g) 6, (h) 10, (i) 11, (j) 14, (k) 18, and (l) 19, 1992 above the Dumont d'Urville station. Inner- and outer-vortex periods are labeled "IN" and "OUT," respectively. Vertical dotted lines represent the 1- $\sigma$ error on the sonde and lidar measurements, while horizontal bars represent the 1- $\sigma$ error on the MLS measurements.

CAT data by about 5-7 ppbv. Furthermore, innervortex data do not show any denitrification signature which may have been expected from other inner vortex measurements [e.g., Santee et al., 1996] but a rather elevated amount of $\mathrm{HNO}_{3}$ ( $\left.\sim 6-15 \mathrm{ppbv}\right)$. Indeed, because the winter 1992 corresponds to a volcanically perturbed period with increased aerosol amounts, $\mathrm{HNO}_{3}$ could have been strongly depleted from the gas phase by the stratospheric aqueous $\mathrm{H}_{2} \mathrm{SO}_{4}$ aerosol uptake of $\mathrm{H}_{2} \mathrm{O}$ and $\mathrm{HNO}_{3}$ [Carslaw et al., 1995]. However, the Dumont d'Urville station is located just at the edge of the vortex area, and this location corresponds to the "collar" region in which Douglass et al. [1995] already pointed out the existence of a different chemical regime as compared to that of the inner vortex area. This inner-vortex collar regime will be studied in the next section. At $4.6 \mathrm{hPa}, \mathrm{CLAES} \mathrm{HNO}_{3}$ is well reproduced by SLIMCAT: a general negative trend is observed by
CLAES and calculated by SLIMCAT, but the model tends to overestimate the observations.

Globally, $\mathrm{H}_{2} \mathrm{O}$ from MLS V4, the MLS nonlinear retrieval, and SLIMCAT agree qualitatively well with a signature of dehydration within the vortex at $46 \mathrm{hPa}$ and a signature of "rehydration" (increased $\mathrm{H}_{2} \mathrm{O}$ due to $\mathrm{CH}_{4}$ oxidation in the upper stratosphere, followed by descent) at $4.6 \mathrm{hPa}$ in the vortex. More precisely, at $46 \mathrm{hPa}$, water vapor, as deduced from MLS V4 and from nonlinear retrievals, compares very well with SLIMCAT results inside the vortex, but measurements show a wetter atmosphere by about 1 ppmv than SLIMCAT outside the vortex. At $4.6 \mathrm{hPa}$, the agreement between SLIMCAT and MLS version 4 data is excellent, while nonlinear retrievals appear to show an atmosphere systematically drier by about $1 \mathrm{ppmv}$.

In the lower stratosphere $(46 \mathrm{hPa}), \mathrm{N}_{2} \mathrm{O}$ temporal evolution from the SLIMCAT model is relatively dif- 

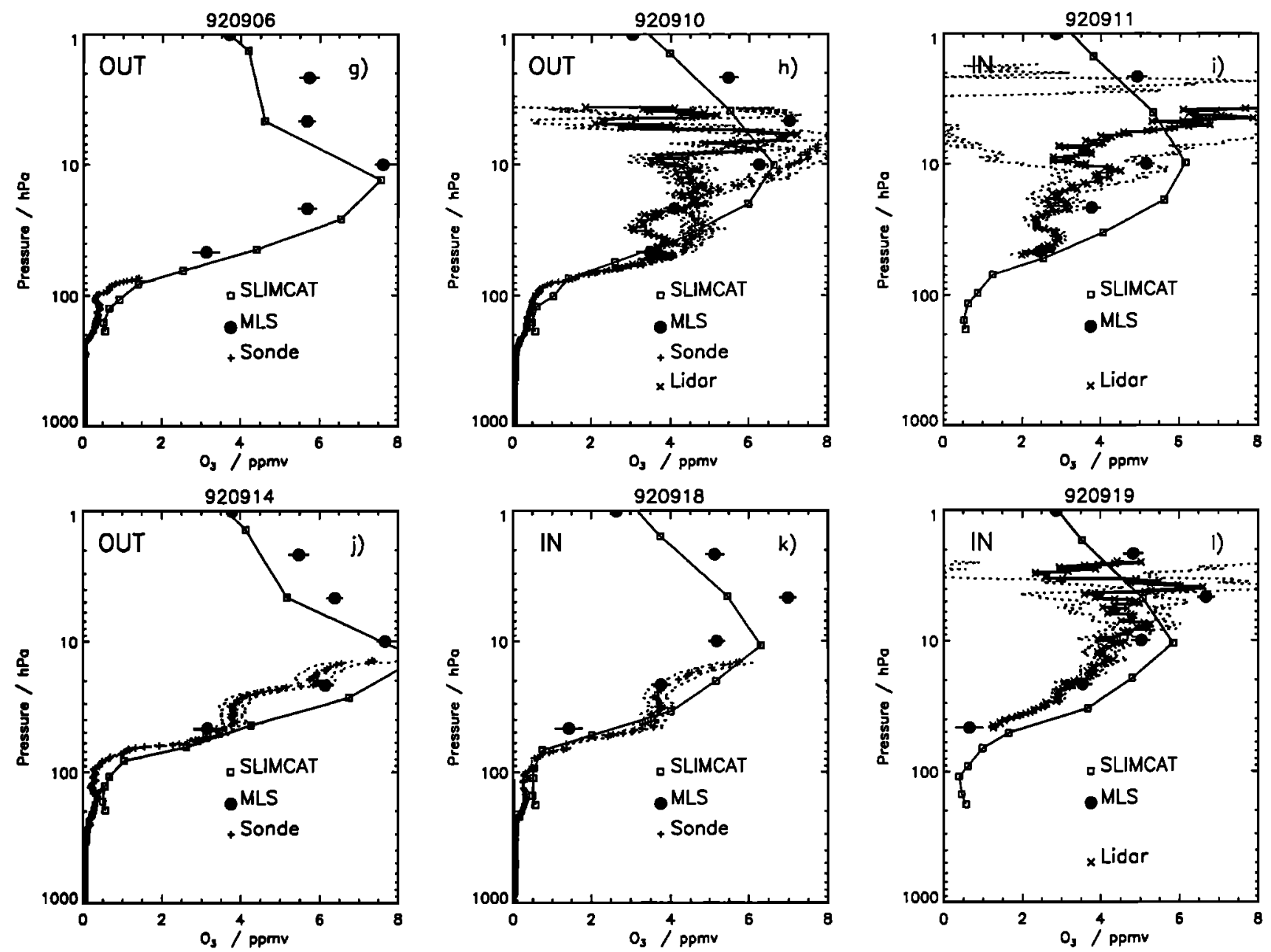

Figure 4. (continued)

ferent from the CLAES data: constant at about 0.2 ppbv for SLIMCAT, while CLAES data show a negative trend from $\sim 0.2 \mathrm{ppbv}$ at the beginning of the 1month period to about $0.1 \mathrm{ppbv}$ at the end. At 4.6 $\mathrm{hPa}$, however, the agreement between SLIMCAT and UARS is excellent both in the temporal evolution and in the absolute value of the $\mathrm{N}_{2} \mathrm{O}$ field with more intense amounts outside than inside the vortex. Interestingly, the same remarks as the $\mathrm{N}_{2} \mathrm{O}$ fields can be applied to the $\mathrm{CH}_{4}$ fields measured by CLAES and calculated by SLIMCAT at 46 and $4.6 \mathrm{hPa}$.

Daytime $\mathrm{ClONO}_{2}$ amounts calculated by SLIMCAT at the same LST as the UARS measurements track the same features as UARS $\mathrm{ClONO}_{2}$ data sets at $46 \mathrm{hPa}$ except that the inner-outer vortex amplitude is much more pronounced in the UARS data $(\sim 1.5 \mathrm{ppbv})$ than in the SLIMCAT data ( 0.5 ppbv). There is a positive trend in both data sets globally over the whole period. At $4.6 \mathrm{hPa}$, the agreement between SLIMCAT and UARS daytime ClONO${ }_{2}$ is impressively good, with a net decrease around September 2, 1992, associated with a change in the LST of the measurements from 0800 to 1600 .
Finally, at $46 \mathrm{hPa}$, daytime $\mathrm{NO}_{2}$ from SLIMCAT ( $\sim 0.2 \mathrm{ppbv}$ ) is significantly lower than UARS measurements $(\sim 0.5-1.0 \mathrm{ppbv})$. The slight increase in $\mathrm{NO}_{2}$ calculated by the model cannot be observed by UARS since its amplitude is within the error bars. The Version 7 $\mathrm{NO}_{2}$ has been shown to have reasonable spatial and temporal morphology [see Reburn et al., 1996]. However, the mixing ratios are biased low throughout most of the stratosphere compared to other sources [Dessler et al., 1996]. In polar winter, lower stratosphere is a region of low reliability for the Version $7 \mathrm{NO}_{2}$ mixing ratio, and it is generally found to be biased higher than other measurements. At $4.6 \mathrm{hPa}$, once again, the comparison between SLIMCAT and UARS is excellent with a net increase in $\mathrm{NO}_{2}$ of about $2 \mathrm{ppbv}$ for UARS and 4 ppbv for SLIMCAT on September 2, 1992, when LST moves from 0800 to 1600 .

\section{Loss and Production Rates}

We now concentrate the analysis on the lowermost stratosphere $(46 \mathrm{hPa}$ ) by selecting days when the station is located conservatively inside the vortex, that is, 


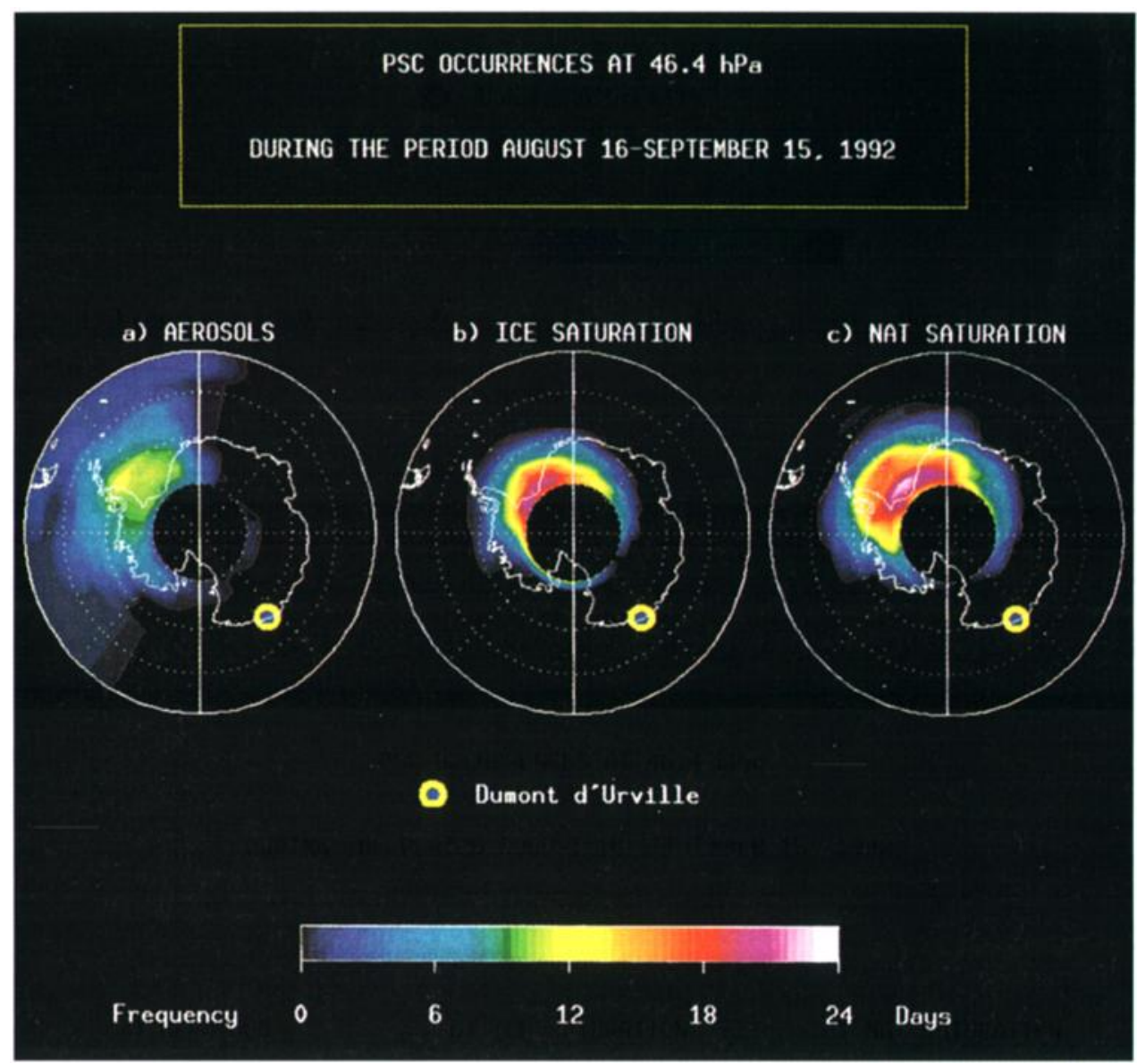

Plate 1. Polar stereographic projection of PSC occurrences (number of days) at $46 \mathrm{hPa}$ over the period August 16 to September 15, 1992, determined from (a) UARS/CLAES extinction coefficients greater than $2 \times 10^{-3} \mathrm{~km}^{-1}$, (b) $60 \%$ ice saturation, and (c) $100 \%$ NAT supersaturation. The yellow solid circle represents the location of the Dumont d'Urville station.

when $|\mathrm{PV}|$ values are greater than 62 PVU. The associated measurements are thus representative of the collar region, as discussed above. Figure 5 shows the temporal evolution of $\mathrm{O}_{3}$, daytime $\mathrm{ClO}$, and daytime $\mathrm{ClONO}_{2}$ measured by UARS and calculated by SLIMCAT at 46 $\mathrm{hPa}$ in the collar region along with the temporal evolution of daytime $\mathrm{HCl}$ deduced from SLIMCAT. Daytime measurements and calculations are performed at the same LST. Together with MLS and SLIMCAT $\mathrm{O}_{3}$, we plot lidar and sonde data (5 days) for the periods when the station is inside the vortex. Measurements from MLS show an obvious decrease in the $\mathrm{O}_{3}$ field of about $0.04 \mathrm{ppmv} \mathrm{d}^{-1}$ that corresponds to about $1.3 \%$ $\mathrm{d}^{-1}$, whereas SLIMCAT estimates the $\mathrm{O}_{3}$ loss in this region to be much less intense: about $0.01 \mathrm{ppmv} \mathrm{d}^{-1}(0.3$ $\left.\% \mathrm{~d}^{-1}\right)$. The $\mathrm{O}_{3}$ loss estimated from MLS measurements is very close to previous vortex measurements and calculations [e.g., Anderson et al., 1991; Manney et al., 1996; MacKenzie et al., 1996] that give an $\mathrm{O}_{3}$ loss of about $1 \% \mathrm{~d}^{-1}$ in the lower stratosphere. Furthermore, lidar and sonde measurements tend to follow more closely the MLS $\mathrm{O}_{3}$ trend than the SLIMCAT $\mathrm{O}_{3}$ trend. We must note that our estimation of the $\mathrm{O}_{3}$ loss at $46 \mathrm{hPa}$ is not the actual chemically induced $\mathrm{O}_{3}$ loss since subsidence effects, as noted in section 3.2, can bring $\mathrm{O}_{3}$-rich air from upper layers during the 1-month period. Thus this figure can be considered as a lower limit of the purely chemically induced $\mathrm{O}_{3}$ loss.

The temporal evolution of $\mathrm{ClO}$ is much more dependent upon the LST of the MLS measurements, and a loss rate of about $0.03 \mathrm{ppbv} \mathrm{d}^{-1}$ is estimated. Santee et al. [1996] estimate a ClO loss of about 0.3 and $0.4 \mathrm{ppbv}$ at 585 and $465 \mathrm{~K}$, respectively, over 15 days that represents a loss of 0.02 and $0.03 \mathrm{ppbv} \mathrm{d}^{-1}$, respectively. The analysis performed by Santee et al. [1996] used UARS/MLS measurements located deep inside the vortex. These figures differ significantly from the $\mathrm{ClO}$ loss rate estimated to be $0.006 \mathrm{ppbv}^{-1}$ by SLIMCAT at the same LST as MLS.

Daytime $\mathrm{ClONO}_{2}$ production rate is estimated to be about $0.025 \mathrm{ppbv} \mathrm{d}^{-1}$ from CLAES measurements, and about half of that by SLIMCAT, that is, $0.01 \mathrm{ppbv}$ $\mathrm{d}^{-1}$. Furthermore, although there are no UARS measurements, SLIMCAT predicts an $\mathrm{HCl}$ production rate of about $0.008 \mathrm{ppbv} \mathrm{d}^{-1}$. The difference observed between UARS and SLIMCAT loss and production rates 


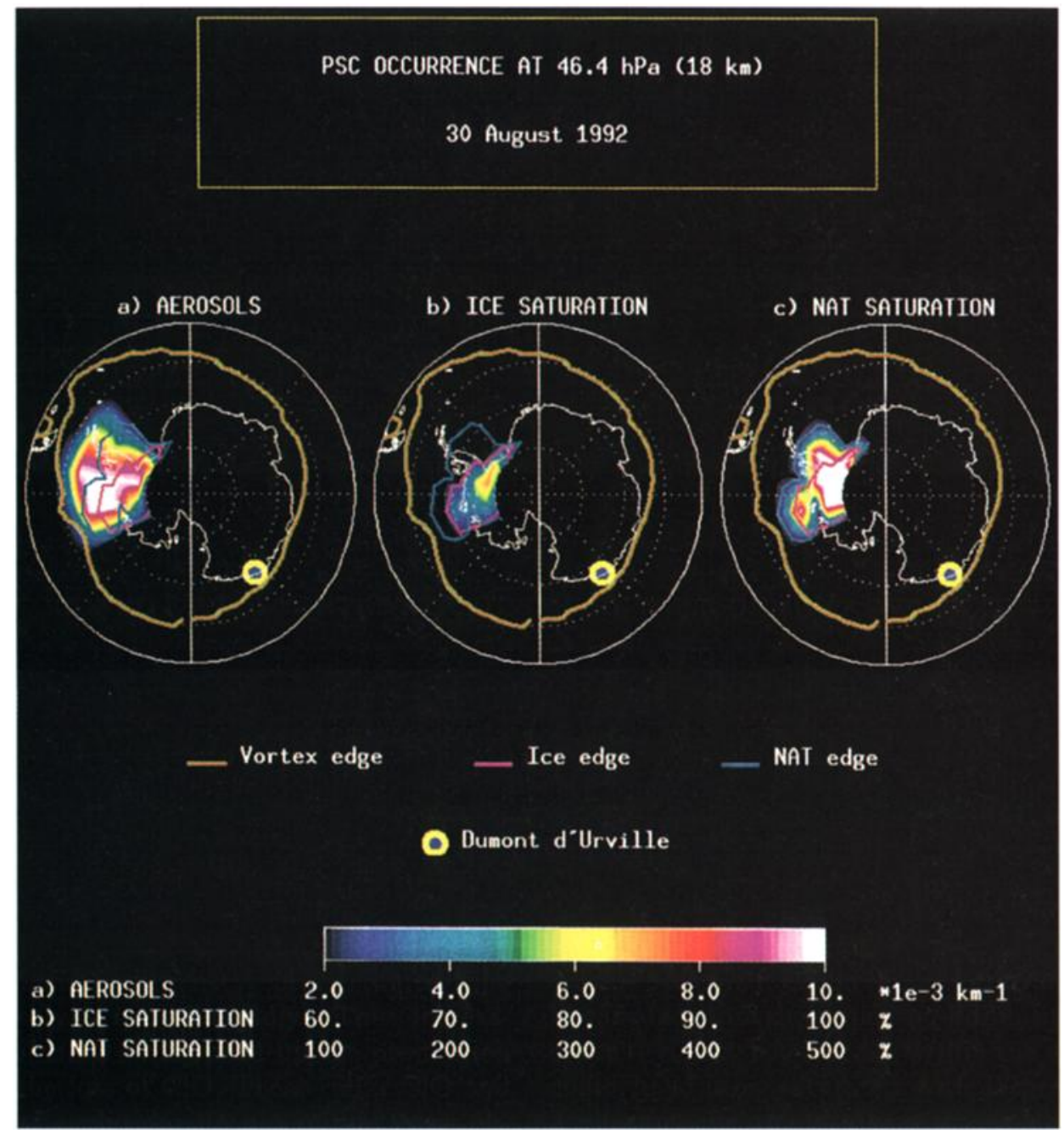

Plate 2. Polar stereographic projection of UARS/ CLAES extinction coefficients, ice saturation, and NAT supersaturation at $46 \mathrm{hPa}$ on August 30,1992, in order to estimate the occurrence of PSC events. The vortex edge $(|\mathrm{PV}|=62 \mathrm{PVU})$ is represented by a yellow line; the edge of the $60 \%$ ice saturation domain is represented by a pink line, and the edge of the $100 \%$ NAT supersaturation is represented by a blue line. The yellow solid circle represents the location of the Dumont d'Urville station.

may originate in the amount of $\mathrm{HNO}_{3}$ present in the collar region since, on average, MLS and CLAES observe mixing ratios of 8-14 ppbv, whereas SLIMCAT estimates an amount of 5-8 ppbv of $\mathrm{HNO}_{3}$. Indeed, Prather and Jaffe [1990] and Douglass et al. [1995] note that when the $\mathrm{O}_{3}$ remains larger than $0.5 \mathrm{ppmv}$, as is the case in our analysis, $\mathrm{ClONO}_{2}$ production arising from $\mathrm{HNO}_{3}$ photolysis occurs rapidly. Thus increasing the amount of $\mathrm{HNO}_{3}$ will speed up the production of $\mathrm{ClONO}_{2}$ and the loss of ClO. These collar ClO and $\mathrm{ClONO}_{2}$ temporal evolutions do not mimic those observed by Santee et al. [1996] from UARS/MLS measurements located deep inside the vortex since, in their case, the atmosphere was almost completely denitrified and $\mathrm{O}_{3}$ mixing ratios were small (less than $0.5 \mathrm{ppmv}$ ); thus $\mathrm{ClONO}_{2}$ could not come from $\mathrm{HNO}_{3}$ photolysis, and $\mathrm{ClO}$ remained stable, enabling the production of $\mathrm{HCl}$ [Douglass et al., 1995].

\section{PSC Occurrence}

As mentioned in section 3, there is no trace of PSC events over the Dumont d'Urville station from midAugust to mid-September 1992 at and above $46 \mathrm{hPa}$. We took the opportunity of using $\mathrm{MLS} \mathrm{H}_{2} \mathrm{O}$ data processed with the version 4 algorithm and with a nonlinear algorithm developed at Edinburgh University in order to detect whether air within the vortex at $46 \mathrm{hPa}$ could have been saturated with respect to ice. Such a phenomenon would give a strong probability of the presence of PSCs, usually referred to as type II PSCs. We also used aerosol extinction coefficients as measured by CLAES in the $780 \mathrm{~cm}^{-1}$ band, after Mergenthaler et al. [1997]. A rather similar analysis was already performed by Ricaud et al. [1995] during the period August 30 to September 3, 1992, using $\mathrm{MLS} \mathrm{H}_{2} \mathrm{O}$ Version 3 and the $790 \mathrm{~cm}^{-1}$ band. The main differences with 


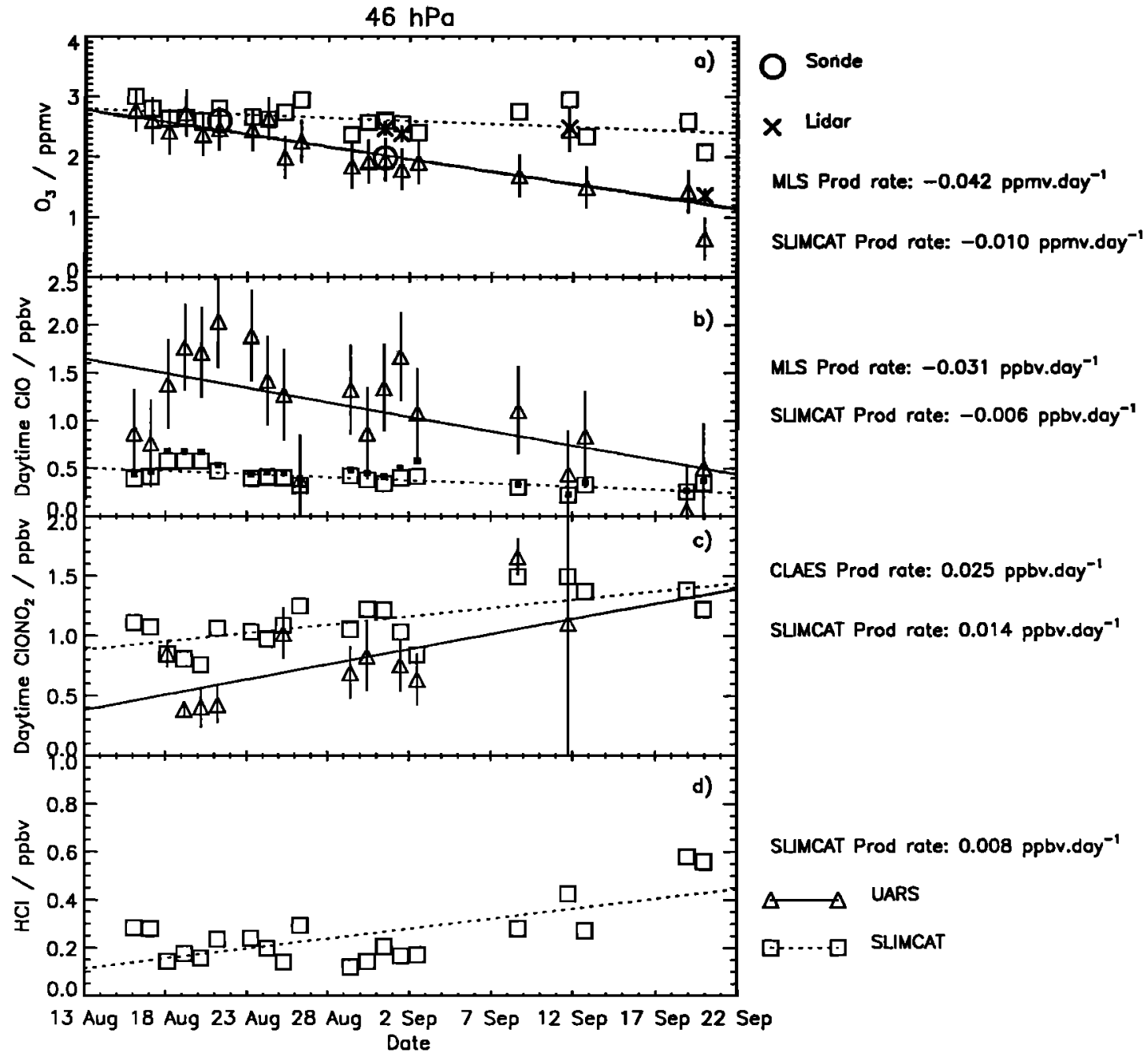

Figure 5. Time series of (a) $\mathrm{O}_{3}$, (b) daytime $\mathrm{ClO}$, (c) daytime $\mathrm{ClONO}_{2}$, and (d) daytime $\mathrm{HCl}$ as measured by UARS (triangles) and as deduced from SLIMCAT (squares) from August 14 to September 20,1992, when the Dumont d'Urville station is located inside the vortex. Sonde and lidar inner-vortex measurements averaged from 40 to $50 \mathrm{hPa}$ are represented by an open circle and a cross, respectively in Figure 5a. Estimated $\mathrm{ClO}_{x}\left(=\mathrm{ClO}+2 \mathrm{Cl}_{2} \mathrm{O}_{2}\right)$ is represented by a tiny thick square in Figure 5b. Vertical bars represent the 1- $\sigma$ error on the measurements. The solid and the dotted straight lines are evaluated by a linear regression method from UARS and SLIMCAT data temporal evolution, respectively.

the previous work are (1) the use of $\mathrm{H}_{2} \mathrm{O}$ retrievals that are much less contaminated by the a priori information used in the retrieval process; in other words, retrievals are more sensitive to the actual amount of $\mathrm{H}_{2} \mathrm{O}$ at 46 $\mathrm{hPa}$, and (2) the use of CLAES and MLS $\mathrm{HNO}_{3}$ measurements for estimating whether the air is saturated with respect to nitric acid trihydrate (NAT), usually referred to as type I PSCs, using the empirical formula given by Hanson and Mauersberger [1988]. This kind of analysis may provide a strong probability for detecting the presence of PSCs made of aerosols in solid phase but will not directly infer any conclusion about PSCs made of aerosols in liquid phase as supercooled ternary solutions (STS).
Plate 1 shows longitudinal and latitudinal PSC occurrences at $46 \mathrm{hPa}$ over Antarctica in number of days during the period August 16 to September 15, 1992, where CLAES aerosol extinction coefficients are greater than $2 \times 10^{-3} \mathrm{~km}^{-1}$, where air is $60 \%$ saturated with respect to ice and where air is supersaturated (saturation greater than $100 \%$ ) with respect to NAT. We note the very good spatial correlation between high aerosol extinction coefficients and areas saturated with respect to ice and NAT. There is a very strong probability for type I and II PSCs to be present between a third and a half of the 1-month period over the Palmer Peninsula and the Weddell Sea, between $20^{\circ}$ and $80^{\circ}$ west longitude and between $65^{\circ}$ and $80^{\circ}$ south latitude. These results are in 
remarkable agreement with Watterson and Tuck [1989] who show from SAM II satellite measurements a maximum of PSC activity around $60^{\circ} \mathrm{W}$ within the latitude band $72.8^{\circ}-78.7^{\circ} \mathrm{S}$. We also see that over the Dumont d'Urville station (yellow solid circle) there is absolutely no trace of PSC occurrence during this 1-month period. Indeed, the location of high probability of PSC events is strongly correlated with an area where temperature is very low, typically less than $195 \mathrm{~K}$, while the Dumont d'Urville station is statistically in the warmer part of the vortex when it is located inside the vortex.

Plate 2 shows, like Plate 1, the longitudinal and latitudinal PSC occurrence at $46 \mathrm{hPa}$ over Antarctica on a particular day, namely August 30, 1992. We note again that there is no trace of PSC events, even when the Dumont d'Urville station is located inside the vortex. There are some strong signals in the CLAES aerosol extinction coefficients over the Bellinghausen Sea, the Palmer Peninsula, and the Weddell Sea $\left(45^{\circ}-120^{\circ} \mathrm{W}\right.$ and $60^{\circ}-80^{\circ} \mathrm{S}$ ), in very good correlation with air being $60 \%$ saturated with respect to ice and supersaturated with respect to NAT by a factor greater than 3 . The degree of ice saturation is very dependent upon (1) the amount of $\mathrm{H}_{2} \mathrm{O}$, but version 4 retrievals and nonlinear processes give roughly the same results, and (2) temperature. We mentioned in section 3 that MLS V4 temperatures at $46 \mathrm{hPa}$ were greater than the UKMO analyses. Since Massie et al. [1994] already compared UKMO temperatures with radiosondes in the southern hemisphere during August 1992 and found that they were slightly warmer by about $0.7 \mathrm{~K}$, we can certainly infer degrees of ice saturation much greater than the one given by using MLS temperatures. Furthermore, Del Negro et al. [1997] mention that in Antarctica winter measurements, conditions of supersaturation with respect to NAT by greater than a factor of 10 are observed and that best agreements are found with STS composition as compared to NAT composition. Also, reprocessed data from infrared measurements performed in 1987 by Toon and Tolbert [1995] have led to the conclusion that observed Antarctic PSCs were not composed of NAT but were more consistent with STS. On the other hand, Koop et al. [1997] show that liquid and solid particles can exist in equilibrium over a wide range of conditions. Finally, using UARS data, we are able to detect thick clouds, but the present analysis is unable to discriminate clouds in liquid and/or solid aerosols, while there are some strong indirect indications (high NAT supersaturation and ice undersaturation) that the clouds are composed of liquid particles.

\section{Conclusions}

The temporal evolution of stratospheric constituents measured by ground-based instruments (lidar and SAOZ) sondes, and satellite-borne instruments (UARS/MLS, UARS/CLAES, and NIMBUS 7/TOMS) along with calculations from the SLIMCAT 3-D model and assimilated data sets (UKMO and ECMWF), over the Dumont d'Urville station, Antarctica $\left(67^{\circ} \mathrm{S}, 140^{\circ} \mathrm{E}\right)$ from August 14 to September 20, 1992, has been analyzed. The analysis shows that the station is located at the vicinity of the vortex edge (either inside or outside the vortex) and thus is representative of a region usually referred to as the "collar" region.

We have found a general agreement between measured data sets throughout the stratosphere, and a better agreement between model and measurements in the middle stratosphere than in the lower stratosphere. At $46 \mathrm{hPa}$, we observe ClO being activated inside the vortex, with a stratosphere dehydrated at $46 \mathrm{hPa}$ and rehydrated above, with no trace of denitrification, which is the signature of the collar region. Loss rates of $\mathrm{O}_{3}$ and $\mathrm{ClO}$ together with production rates of $\mathrm{ClONO}_{2}$ are measured to be greater than modeled, probably because the SLIMCAT model estimates an atmosphere slightly denitrified that reduces the $\mathrm{ClONO}_{2}$ production (and ClO loss) through the photolysis of $\mathrm{HNO}_{3}$ and because it does not have a horizontal resolution high enough for the present analysis.

Finally, we have not observed any PSC events above the station and have shown that they are exclusively contained above the Palmer Peninsula area for this time period. There are some indirect indications for clouds to be composed of liquid supercooled ternary solutions. A quantification of the composition of the detected clouds is beyond the scope of the present paper but may be a step further in the evolution of the "Antarctica 1992" project.

Acknowledgments. The authors acknowledge the Institut Français pour la Recherche et la Technologie Polaires (IFRTP) for providing support to the Stratospheric Ozone project at Dumont d'Urville, many colleagues who have contributed to the MLS and CLAES experiments (in particular NASA and the UARS project office), R. McPeters at NASA GSFC for the TOMS V7 overpass data, and the U.K. Meteorological Office and the European Centre for Medium-Range Weather Forecasts for the meteorological data. Two of the authors (P.R. and E.M.) would like to thank J. de La Noë at Bordeaux Observatory for his support. This project has been funded in France by the CNRS/INSU, the CNES, and the MENRT.

\section{References}

Anderson, J. G., D. W. Toohey, and W. H. Brune, Free radicals within the Antarctic vortex: The role of CFCs in Antarctic ozone loss, Science, 251, 39-46, 1991.

Barath, F., et al., The Upper Atmosphere Research Satellite Microwave Limb Sounder instrument, J. Geophys. Res., 98, 10,751-10,762, 1993.

Carslaw, K. S., B. Luo, and T. Peter, An analytic expression for the composition of aqueous $\mathrm{HNO}_{3}-\mathrm{H}_{2} \mathrm{SO}_{4}$ stratospheric aerosols including gas phase removal of $\mathrm{HNO}_{3}$, Geophys. Res. Lett., 22, 1877-1880, 1995.

Chipperfield, M. P., M. L. Santee, L. Froidevaux, G. L. Manney, W. G. Read, J. W. Waters, M. A. E. Roche, and J. M. Russell, Analysis of UARS data in the southern polar 
vortex in September 1992 using chemical transport model, J. Geophys. Res., 101, 18,861-18,881, 1996.

Del Negro, L. A., et al., Evaluating the role of NAT, NAD, and liquid $\mathrm{H}_{2} \mathrm{SO}_{4} / \mathrm{H}_{2} \mathrm{O} / \mathrm{HNO}_{3}$ solutions in Antarctic polar stratospheric cloud aerosol: Observations and implications, J. Geophys. Res., 102, 13,255-13,282, 1997.

Dessler, A. E., S. R. Kawa, A. R. Douglass, D. B. Considine, J. B. Kumer, A. E. Roche, J. L. Mergenthaler, J. W. Waters, J. M. Russell III, and J. C. Gille, A test of partitioning between $\mathrm{ClO}$ and $\mathrm{ClONO}_{2}$ using simultaneous UARS measurements of $\mathrm{ClO}, \mathrm{NO}_{2}$, and $\mathrm{ClONO}_{2}, J$. Geophys. Res., 101, 12,515-12,521, 1996.

Douglass, A. R., M. R. Schoeberl, R. S. Stolarski, J. W. Waters, J. M. Russell III, A. E. Roche, and S. T. Massie, Interhemispheric differences in springtime production of $\mathrm{HCl}$ and $\mathrm{ClONO}_{2}$ in the polar vortices, J. Geophys. Res., 100, 13,967-13,978, 1995.

Godin S., et al., Systematic stratospheric observations on the Antarctic continent at Dumont d'Urville, NASA Conf. Publ., 3266, 1994a.

Godin S., C. David, and M. Guirlet, Evolution of the Mt. Pinatubo volcanic cloud and analysis of its effect on the ozone amount as observed from ground-based measurements performed in northern and southern latitudes, $\mathrm{Pa}$ per presented at Workshop on the Effect of the Mount Pinatubo Eruption on the Atmosphere and Climate, N. Atl. Treaty Org., Rome, Sept. 1994b.

Goutail, F., J.-P. Pommereau, A. Sarkissian, E. Kyro, and V. Dorohkov, Total nitrogen dioxide at the Arctic polar circle since 1990, Geophys. Res. Lett., 21, 1371-1374, 1994.

Hanson, D., and K. Mauersberger, Laboratory studies of the nitric acid trihydrate: Implications for the south polar stratosphere, Geophys. Res. Lett., 15, 855-858, 1988.

Kondo, Y., W. A. Matthews, S. Solomon, M. Koike, M. Hayashi, K. Yamazaki, H. Nakajima, and K. Tsukui, Ground-based measurements of column amounts of $\mathrm{NO}_{2}$ over Syowa station, Antarctica, J. Geophys. Res., 99, 14,535-14,548, 1994.

Koop, T., K. S. Carslaw, and T. Peter, Thermodynamic stability and phase transitions of PSC particles, Geophys. Res. Lett., 24, 2199-2202, 1997.

Lateltin, E., J.-P. Pommereau, H. LeTexier, M. Pirre, and R. Ramaroson, Perturbation of stratospheric nitrogen dioxide by volcanic aerosol in the arctic, Geophys. Res. Lett. 21, 1411-1414, 1994.

MacKenzie, I. A., R. S. Harwood, L. Froidevaux, W. G. Read, and J. W. Waters, Chemical loss of polar vortex ozone inferred from UARS MLS measurements of ClO during the Artic and Antarctic late winters of 1993, $J$ Geophys. Res., 101, 14,505-14,518, 1996.

Manney, G. L., R. Swinbank, S. T. Massie, M. E. Gelman, A. J. Miller, R. Nagatani, A. O'Neill, and R. W. Zurek, Comparison of U.K. Meteorological Office and U.S. National Meteorological Center stratospheric analyses during northern and southern winter, J. Geophys. Res., 101, 10,311-10,334, 1996

Massie, S. T., P. L. Bailey, J. C. Gille, E. C. Lee, J. L. Mergenthaler, A. E. Roche, J. B. Kumer, E. F. Fishbein, J. W. Waters, and W. A. Lahoz, Spectral signatures of polar stratospheric clouds and sulfate aerosols, J. Atmos. Sci., 51, 3027-3044, 1994.

Massie, S. T., et al., Validation studies using multiwavelength Cryogenic Limb Array Etalon Spectrometer (CLAES) observations of stratospheric aerosol, J. Geophys. Res., 101, 9757-9773, 1996.

Massie, S. T., et al., Simultaneous observations of polar stratospheric clouds and $\mathrm{HNO}_{3}$ over Scandinavia in January 1992, Geophys. Res. Lett., 24, 595-598, 1997.
Mergenthaler, J. L., J. B. Kumer, A. E. Roche, and S. T. Massie, The distribution of Antarctic polar stratospheric clouds as seen by the CLAES Experiment on UARS, $J$. Geophys. Res., in press, 1997.

Pommereau, J.-P., and F. Goutail, Stratospheric $\mathrm{O}_{3}$ and $\mathrm{NO}_{2}$ observations at the southern polar circle in summer and fall 1988, Geophys. Res. Lett., 15, 895-897, 1988.

Pommereau, J.-P., and J. Piquard, Ozone, nitrogen dioxide, and aerosol vertical distributions by UV-visible solar occultation from balloons, Geophys. Res. Lett., 21, 12271230, 1994.

Pommereau, J.-P., F. Goutail, and A. Sarkissian, SAOZ total ozone measurements in Antarctica: Comparisons with TOMS versions 6 and 7, in Proceedings of the 3rd European Symposium on Polar Ozone, Atmospheric Pollution, Rep. 56, pp. 516-520, Eur. Comm., 1996.

Prather, M., and A. H. Jafle, Global impact of the Antarctic ozone hole: Chemical propagation, J. Geophys. Res., 95, 3473-3492, 1990.

Reburn, W. J., J. J. Remedios, P. E. Morris, C. D. Rodgers, F. W. Taylor, B. J. Kerridge, J. Ballard, J. B. Kumer, and S. T. Massie, Validation of nitrogen dioxide measurements from the Improved Stratospheric and Mesospheric Sounder, J. Geophys. Res., 101, 9873-9895, 1996.

Ricaud, P. D., et al., Polar stratospheric clouds as deduced from MLS and CLAES measurements, Geophys. Res. Lett., 22, 2033-2036, 1995.

Roche, A. E., J. B. Kumer, J. L. Mergenthaler, G. A. Ely, W. G. Uplinger, J. F. Potter, T. C. James, and L. W. Sterritt, The Cryogenic Limb Array Etalon Spectrometer (CLAES) on UARS: Experiment description and performance, J. Geophys. Res., 98, 10,763-10,775, 1993.

Roche, A. E., et al., Validation of $\mathrm{CH} 4$ and $\mathrm{N} 2 \mathrm{O}$ measurements by the cryogenic limb array etalon spectrometer instrument on the Upper Atmosphere Research Satellite, J. Geophys. Res., 101, 9679-9710, 1996.

Roscoe, H. K., A. E. Jones, and A. M. Lee, Midwinter start to Antarctic ozone depletion: Evidence from observations and models, Science, 278, 93-96, 1997.

Russell, J. M., III, L. L. Gordley, J. H. Park, S. R. Drayson, W. D. Hesketh, R. J. Cicerone, A. F. Tuck, J. E. Frederick, J. E. Harries, and P. J. Crutzen, The Halogen Occultation Experiment, J. Geophys. Res., 98, 10,777-10,797, 1993.

Santee, M. L., W. G. Read, J. W. Waters, L. Froidevaux, G. L. Manney, D. A. Flower, R. F. Jarnot, R. S. Harwood, and G. E. Peckham, Interhemispheric differences in polar stratospheric $\mathrm{HNO}_{3}, \mathrm{H} 2 \mathrm{O}, \mathrm{ClO}$ and $\mathrm{O}_{3}$, Science, 267, 849852, 1995.

Santee, M. L., L. Froidevaux, G. L. Manney, W. G. Read, J. W. Waters, M. P. Chipperfield, A. E. Roche, J. B. Kumer, J. L. Mergenthaler, and J. M. Russell III, Chlorine deactivation in the lower stratospheric polar regions during late winter: Results from UARS, J. Geophys. Res., 101, 18,835-18,859, 1996.

Sarkissian, A., J.-P. Pommereau, F. Goutail, and E. Kyro, PSC and volcanic aerosol observations during EASOE by UV-visible ground-based spectrometry, Geophys. Res. Lett., 21, 1319-1322, 1994.

Solomon, S., Progress towards a quantitative understanding of Antarctic ozone depletion, Nature, 347, 347-354, 1990.

Stefanutti, L., F. Castagnolli, M. Del Guasta, M. Morandi, V. M. Sacco, L. Zuccagnolli, S. Godin, G. Megie, and J. Porteneuve, The Antarctic Ozone Lidar System, Appl. Phys. B, 55, 3-12, 1992.

Toon, G. C., C. B. Farmer, L. L. Lowes, P. W. Schaper, J. F. Blavier, and R. H. Norton, Infrared aircraft measurements of stratospheric composition over Antarctica during September 1987, J. Geophys. Res., 94, 16,571-16,596, 1989. 
Toon, O. B., and M. A. Tolbert, Spectroscopic evidence against nitric acid trihydrate in polar stratospheric clouds, Nature, 375, 218-221, 1995.

Turco, R. P., O. B. Toon, and P. Hamill, Heterogeneous physicochemistry of the polar ozone hole, J. Geophys. Res., 94, 16,493-16,510, 1989.

Waters, J. W., Microwave limb sounding, in Atmospheric Remote Sensing by Microwave Radiometry, edited by M. A. Janssen, pp. 383-496, John Wiley, New York, 1993.

Waters, J. W., L. Froidevaux, W. G. Read, G. L. Manney, L. S. Elson, D. A. Flower, R. F. Jarnot, and R. S. Harwood, Stratospheric ClO and ozone from the Microwave Limb Sounder on the Upper Atmosphere Research Satellite, Nature, 362, 597-602, 1993.

Watterson, I. G., and A. F. Tuck, A comparison of the longitudinal distributions of polar stratospheric clouds and temperatures for the 1987 antarctic spring, J. Geophys. Res., 94, 16,511-16,525, 1989.

M. P. Chipperfield, Department of Chemistry, University of Cambridge, Lensfield Road, Cambridge, CB2 1EW, England.
C. David and S. Godin, Service d'Aéronomie du CNRS, Université de Jussieu, 4 Place Jussieu, 75252 Paris Cedex 05, France.

L. Froidevaux and J. W. Waters, Jet Propulsion Laboratory, 4800 Oak Grove Drive, Pasadena, 91109-8099, California.

F. Goutail and J.-P. Pommereau, Service d'Aéronomie du CNRS, BP 3, 91371, Verrières-Le-Buisson, France.

J. Mergenthaler and A. E. Roche, Lockheed Martin Advanced Technology Center, Palo Alto, 94304, California.

H. Pumphrey, Department of Meteorology, University of Edinburgh, Edinburgh, EH9 3JZ, Scotland.

Ph. Ricaud and E. Monnier, Bordeaux Observatory, CNRS/INSU, BP 89, 33270, Floirac, France. (e-mail: ricaud@observ.u-bordeaux.fr)

(Received November 25, 1997; revised February 16, 1998; accepted February 24, 1998.) 